Mirai. Estudios Japoneses

ISSN-e: 2531-145X

http://dx.doi.org/10.5209/mira.67520

\title{
La presencia de Oriente en tres dancings barceloneses de los años 30: Oshima,
} Wu Li Chang y La Criolla

\author{
Juan Carlos Calvo Asensio (iD, Pablo Cercós Maícas (iD), Marc Millan Rabasa ${ }^{1}$
}

Resumen. La relación entre Oriente y Occidente estuvo presente desde la antigüedad, aunque la industrialización aceleró el acercamiento entre ambos mundos. En nuestro país, la cultura de China y de Japón tuvo una influencia especialmente intensa en la ciudad de Barcelona desde mediados del siglo XIX hasta la Guerra Civil. En el presente artículo estudiamos esta conexión exponiendo el impacto de ambos países en el ambiente festivo, arquitectónico y decorativo de tres dancings barceloneses de los años 30 del siglo pasado: Oshima, Wu Li Chang y La Criolla. Para comprenderlos, explicaremos los fenómenos del japonismo y la tardo-chinoiserie a partir de las Exposiciones de 1888 y 1929. A continuación, mediante fotografías históricas y notas de prensa, ahondaremos en la historia de estos tres locales y el uso de la temática oriental para atraer, en un caso, a la burguesía catalana y, en los otros dos, a las clases populares.

Palabras clave: Dancing; China; Japón; Barcelona; años 30.

\section{[en] The presence of Orient in three Barcelonese cabarets of the 1930's: Oshima, Wu Li Chang and La Criolla}

\begin{abstract}
The relationship between Occident and Orient began in the Ancient era but the industrialization turned both realities even closer. In Spain, Chinese and Japanese cultures had an intense influence in Barcelona from the second half of the 19th century until the Spanish Civil War. In this paper we study this connection, paying special attention to the architectural and decorative style of three Barcelonese cabarets of the Thirties: Oshima, Wu Li Chang and La Criolla. We introduce our text speaking about the impact of japonisme and the late chinoiserie after de Exhibitions of 1888 and 1929. In addition, we analyze the history of these three bars using historical photographs and the newspapers archives to explain how one of them used the oriental theme as an attraction for the Catalan bourgeoisie while the two others enticed the working class.
\end{abstract}

Keywords: Cabaret; China; Japan; Barcelona; Thirties.

Sumario. 1. El impacto de China y Japón en Barcelona a partir de la Exposición Universal de 1888 y la Exposición Internacional de 1929; 2. Dancing Oshima (1935-1938), un salón japonés para la aristocracia barcelonesa; 3. Dos cabarets del barrio Chino con aroma al Lejano Oriente: Dancing Wu Li Chang (1932-1938) y La Criolla (1925-1938); 4. Conclusión; 5. Bibliografía.

Cómo citar: Calvo J. C., Cercós, P. y Millan, M. La presencia de Oriente en tres dancings barceloneses de los años 30: Oshima, Wu Li Chang y La Criolla, en Mirai. Estudios Japoneses, 4, 2020, 143-160.

\section{El impacto de China y Japón en Barcelona a partir de la Exposición Universal de 1888 y la Exposición Internacional de 1929}

El siglo XIX significó el inicio de una nueva etapa en las relaciones con Oriente. El furor que China había generado en la Europa dieciochesca, que se concretó en el fenómeno de las chinerías, se fue diluyendo lentamente. Mientras, tras la Restauración Meiji, Japón destronaría al gigante asiático como el gran seductor de Occidente. La cultura japonesa se extendió rápidamente debido a las nuevas transacciones comerciales y las exposiciones universales e internacionales, donde el país se presentó como una nación moderna a la manera europea y, al mismo tiempo, de tradiciones arraigadas ${ }^{2}$. Ambos aspectos resultaron especialmente atrayentes, el primero porque alimentaba el ego

Graduados en Historia del Arte. El presente texto es una adaptación del audiovisual titulado Oshima y Wu Li Chang. Dos dancings orientales en la Barcelona de los años 30, que obtuvo el primer premio en el II Certamen Universitario de Microrrelatos sobre Asia 2018/2019 en el marco del proyecto No. 276 del programa INNOVA-docencia de la Universidad Complutense de Madrid. Dicho cortometraje fue tutorizado por la profesora Elena Barlés Báguena, a quien agradecemos su insistencia para que publicásemos este texto y sus recomendaciones para mejorarlo. Contacto: 700413@unizar.es (Juan Carlos Calvo), pablocercosmaicas@gmail.com (Pablo Cercós) y 784416@unizar.es (Marc Millan).

Almazán Tomás, D. (2006): 85-104 
colonial civilizador y el segundo porque el continente asistía a la formación de las identidades nacionales y a la revalorización de las artesanías, en decaimiento tras la Revolución Industrial.

El caso barcelonés es especial en el contexto español por la incidencia tan intensa del japonismo, como ha estudiado Ricard Bru Turull ${ }^{3}$. A la vez, la cultura y el arte chinos generaron el interés de muchos coleccionistas, pero sin alcanzar la misma notoriedad, hecho que conocemos gracias a las publicaciones de Mònica Ginés Blasi ${ }^{4}$. Esta circunstancia estuvo favorecida por el Tratado de Amistad, Comercio y Navegación entre España y Japón, ratificado en $1868^{5}$.

La llegada de ambos territorios a la Ciudad Condal hunde sus raíces en las décadas de 1860 y 1870, cuando se organizaron las primeras exposiciones de arte asiático ${ }^{6}$. Sin embargo, el auge de esta moda se produjo con la celebración de la Exposición Universal de 1888 y tuvo sus últimos coletazos en los años 30 del siglo pasado, avivada por la Exposición Internacional de 1929. Ambos eventos condicionaron la visión que se tenía sobre los dos países.

En la Exposición Universal de 1888, Japón concurrió de manera oficial con una casa tradicional y varios escaparates con todo tipo de manufacturas producidas por la empresa gubernamental Kiritsu Kosho Kaisha. Igualmente, se mostraron fotografías de sus nuevas infraestructuras para alardear de su reciente política de desarrollismo ${ }^{7}$. El País del Lejano Oriente se presentó como una nación moderna y, a la par, poseedora de unas profundas raíces culturales; potenciando su pasado como algo exótico que exportar y su presente como un indicador de progreso.

La muestra implicó la definitiva incorporación de lo japonés al bagaje personal y artístico de muchos artífices que coleccionaron arte nipón o tuvieron conocimiento de su estética. Entre ellos podemos citar a Marià Fortuny, Francesc Masriera, Lluís Masriera, Apel·les Mestres, Pere Ynglada, Alexandre de Riquier, Santiago Rusiñol, Isidre Nonell, Lluís Domènech i Montaner o Antoni Gaudí8.

Cuando los productos del archipiélago se popularizaron, la capital catalana les ofreció una salida comercial. Por toda la ciudad aparecieron tiendas con objetos japoneses, como las de Francesc Vidal, Bruno Cuadros, Odó Vinyals o Santiago Gisbert ${ }^{9}$, que nutrieron las estancias de los hogares burgueses en el recién construido Ensanche. Al mismo tiempo, tenemos constancia de la existencia de numerosas colecciones como las de Josep Mansana, Carles Maristany o Víctor Balaguer, entre muchas otras ${ }^{10}$, y la apertura del Museo Japonés de Richard Lindau entre el paseo de Gracia y la calle Pau Claris ${ }^{11}$. Además, la redacción de monografías y las revistas ilustradas contribuyeron a ampliar el interés y los conocimientos por su cultura ${ }^{12}$.

Desde entonces, la élite cultural catalana se mostró fascinada por el arte japonés e incluso llegó a polemizar con los círculos eruditos madrileños, no tan receptivos después de que el país nipón apoyase la independencia de Filipinas ${ }^{13}$. Debemos recordar que Barcelona era la ciudad peninsular con las mejores conexiones con Asia, pues la Compañía Trasatlántica de Barcelona, en su línea de Filipinas, ofrecía trece viajes anuales con enlaces en Japón, China, la Conchinchina (Vietnam) e India, hecho que fácilmente permite entender su mayor aperturismo ${ }^{14}$.

Por otra parte, la Exposición Internacional de 1929 se encuentra ya en el "epílogo del japonismo", al que se daría carpetazo con la Guerra Civil ${ }^{15}$. Japón, en esta ocasión, no participó de manera oficial. Varios comerciantes se agruparon y expusieron todo tipo de obras bajo la dirección del apodado "señor Misiku". En la entrada de su pabellón se dispuso una gran reproducción del Buda de Kamakura de siete metros de altura [fig. 1] y dos quioscos unidos por un puente, con numerosos estands que formaban un trazado rectilíneo imitando a los barrios comerciales de Tokio ${ }^{16}$. En los escaparates figuraron biombos de Yokohama, mantones "de Cantón" (sic.), lacas de Shizuoka, porcelanas de Kutani y Yoshino, cobres de Tamba, bronces de Osaka, grabados, marfiles, bordados en seda "de Moritesmo" (sic.) y obras de arte de Yoshida. A todo ello se añadieron los platos y tazas de té pintadas que vendían algunos artistas venidos desde el país ${ }^{17}$.

Nos valdremos de sus publicaciones y la hemeroteca para elaborar nuestro breve estudio. No obstante, para profundizar en el tema véase Bru Turull, R. (2004): 233-257; Bru Turull, R. (2008): 1-10; Bru Turull, R. (2012): 60-62; Bru Turull, R. (2016): 41-51 y Bru Turull, R. (2018): 285-300

Al respecto se recomienda consultar Ginés Blasi, M. (2013) y Ginés Blasi, M. (2015): 139-155.

Blat Martínez, A. (2018): 75-88.

Para el caso japonés véase Bru Turull, R. (2004): 235-236 y para el chino léase Ginés Blasi, M. (2015): 139-155.

Bru Turull, R. (2016): 44-48.

8 Fueron muchos más, pero aquí hemos realizado una selección. Sobre cada uno de ellos véase Bru Turull, R. (2004): 233-257. Respecto al caso concreto de Domènech i Montaner léase Bru Turull, R. (2018): 285-300. Por último, aunque no se tiene constancia de que Gaudí coleccionase arte japonés, sí experimentó con algunas soluciones arquitectónicas que evocan a la estética del país, tal como hemos constatado en ibid:: 287.

Barlés Báguena, E. (2015): 108-109.

Bru Turull, R. (2004): 238-250.

Bru Turull, R. (2012): 60-62.

Por ejemplo, con el libro titulado Dai Nipon de Antonio García Llansó. Barlés Báguena, E. (2003): 50.

13 Sobre la lucha entre la modernidad barcelonesa y el conservadurismo madrileño en la apreciación del arte japonés véase Anía Ruiz-Flores, P. C. (2019): 149.

14 Anónimo (1892): 159.

15 Almazán Tomás, D. (2006): 102.

16 Anónimo (1929a): 10.

17 Anónimo (1929b): 33. 


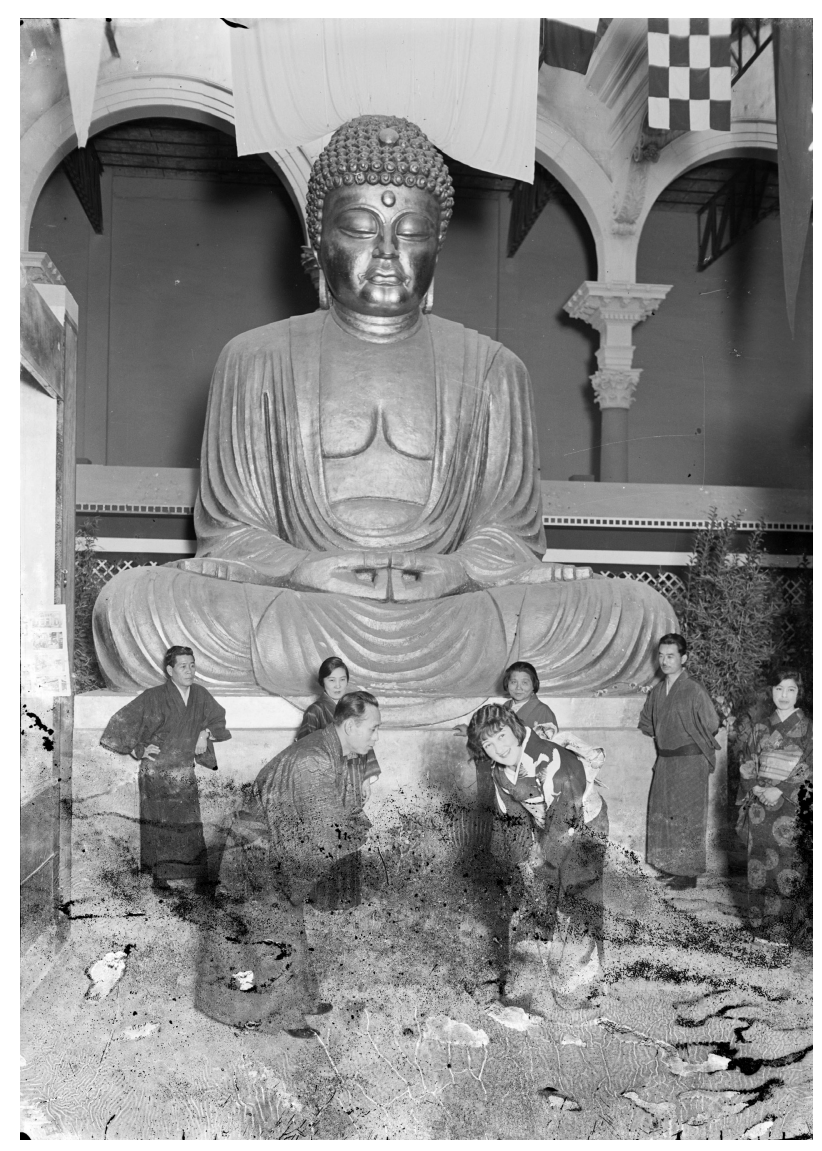

Fig. 1. Estudio Gaspar, Sagarra y Torrents, pabellón de Japón en la

Exposición Internacional de 1929, Arxiu Nacional de Catalunya, ANC1-585-N-6638.

En definitiva, se trató de una apuesta por las manufacturas artesanales, muy similares a las de 1888, que generó menor repercusión mediática, pero que sí agradó al público general y a los artistas. Estos últimos, atraídos por las formas que el arte japonés podía ofrecerles, adaptaron el primer japonismo a la estética del art decó en los años 20 y 30. La influencia estuvo muy presente en los muebles, las lacas, la ilustración ${ }^{18}$, la cerámica o el vestido. Sin embargo, enraizó entonces un interés mucho más profundo hacia aspectos culturales, como la literatura o el teatro, y se intentó formar a oficiales capacitados en las técnicas tradicionales de los artesanos nipones. Era un momento de comprensión y no tanto de imitación ${ }^{19}$.

Por otra parte, las antiguas colecciones siguieron ampliándose y cada vez se hacían más heterogéneas incorporando nuevos objetos. Podemos mencionar en este sentido a los marchantes Joan Artigas Alart, Josep Porta, Joan Fabré i Oliver, Francesc Ferriol, José María Rodríguez-Acosta, José Palacio o Damià Mateu ${ }^{20}$. También se llevaron a cabo algunas iniciativas particulares como la de la Universidad de Barcelona, que patrocinó un crucero para sus estudiantes con destino a la ciudad de Kobe en $1935^{21}$.

Mientras, China asistió a la Exposición de 1888 por la iniciativa privada del comerciante Yong Heng, jefe de una casa comercial de Cantón ${ }^{22}$. Pese a sus esfuerzos por demostrar "el grado de adelanto industrial" del país y su manejo de la lengua castellana, los periodistas hablaron de su sección con cierto descrédito ${ }^{23}$. Esta mala prensa tuvo que ver con el recelo que ocasionaba que el Celeste Imperio gobernase con una mentalidad proteccionista para evitar una invasión extranjera. Además, empezaba a forjarse el mito del peligro amarillo debido al goteo continuo de inmigración hacia los Estados Unidos y Europa ${ }^{24}$.

Por esta razón, aunque la delegación de Yong Heng ocupó una extensión de ciento veinte metros cuadrados [fig. 2] con "porcelanas finísimas y delicadamente pintadas, muebles de corte puramente chino, tintas, sederías riquísimas y productos vegetales rarísimos y curiosos" ${ }^{25}$, la crítica se mostró vehemente y no perdonó lo que consideraba el "adelanto lento" consecuencia del arraigado "tradicionalismo" de una región "sumida en la barbarie"26. En definitiva,

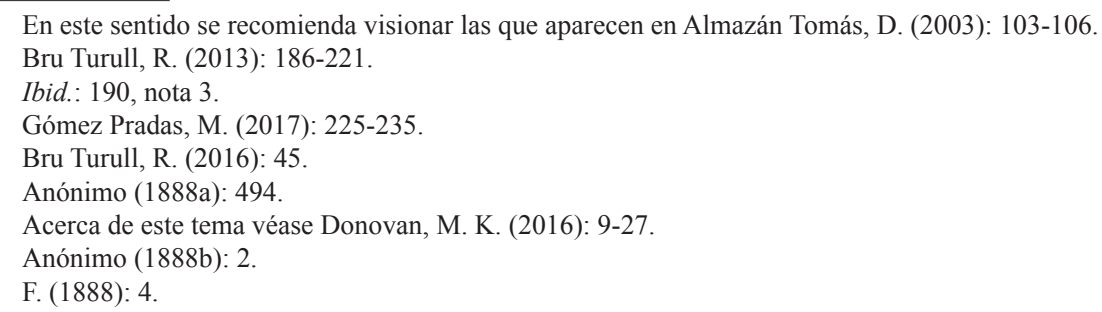


pensaban que se trataba de una muestra "digna de ser visitada" para conocer "la producción de un Estado casi antípoda al nuestro, de un país misterioso y casi desconocido"27. A las masas, por el contrario, parece que sí le entusiasmaron sus artículos, que eran especialmente conocidos por las importaciones filipinas ${ }^{28}$.

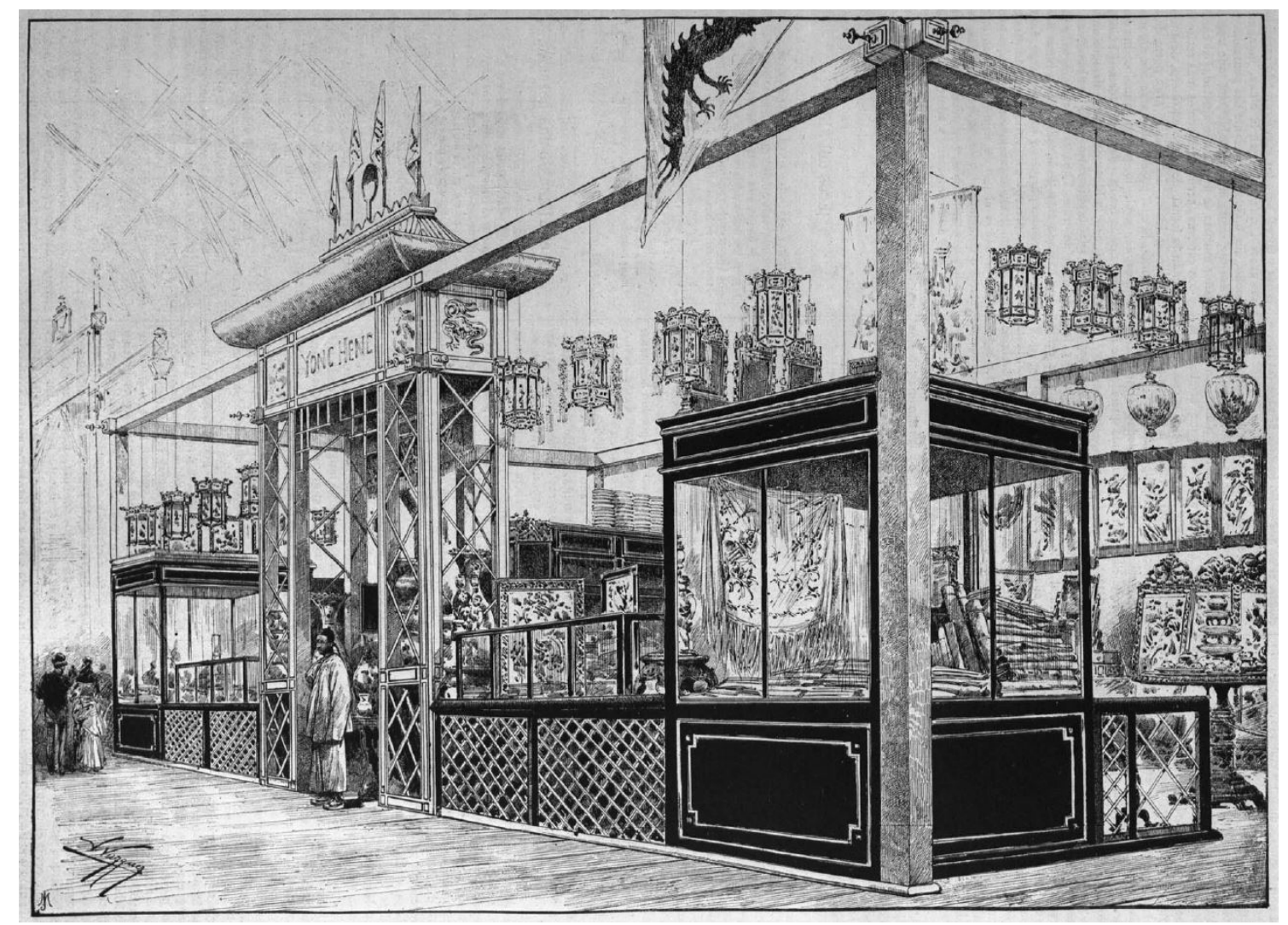

Fig. 2. J. Vázquez, pabellón de Yong Heng en la Exposición Universal de 1888, La Ilustración, Barcelona, 29/07/1888, p. 489, Biblioteca de Catalunya-Arxiu de Revistes Catalanes Antigues.

El Gigante Asiático no participó en la Exposición Internacional de 1929, pero disfrutó de una leve presencia que para nada es equiparable a la recién comentada. Tuvo representación en la Exposición Misional, una actividad englobada dentro del evento dedicada a promocionar la evangelización católica en el mundo, incluyendo las historias de los mártires. En su inauguración se celebró una procesión "cívico-religiosa" con niños de diferentes colegios disfrazados de "infieles" de Japón, China, India y Oceanía ${ }^{29}$. También se dio a conocer el folleto titulado Missions, séminaires, écoles catholiques en Chine -editado en 1927/1928-, hablando de la presencia del cristianismo en la región ${ }^{30}$. Sus instalaciones fueron calificadas como "las más perfectas y sugestivas" de las que se exhibían en el palacio de las Misiones ${ }^{31}$. Contaba con muebles, tapices, cuadros e ídolos ${ }^{32}$, además de maniquíes vestidos con trajes tradicionales sentados a la mesa en una recreación de un interior oriundo ${ }^{33}$.

Como sucedía con Japón, también tenemos constancia de la existencia de colecciones de numismática y arte chinos en este contexto, como las de Eduard Toda i Güell o Juan Mencarini, este último socio de Yong Heng en la Exposición Universal ${ }^{34}$. En la década de 1930 este fenómeno se reavivó y muchos coleccionistas pretendieron "crear salas chinas" en sus residencias privadas, como sucedió con Joan Artigas-Alart Casas y Charles Bouvard ${ }^{35}$. Coetáneamente se produjeron las primeras donaciones de piezas a instituciones públicas, cuando Damià Mateu depositó sus pertenencias en el Museo de Artes Decorativas de la ciudad ${ }^{36}$. El ya mencionado Eduard Toda se encargó de contribuir a la difusión de la cultura china mediante numerosas publicaciones y conferencias ${ }^{37}$.

Como vemos, a partir de las Exposiciones lo japonés quedó vinculado al mundo de la alta cultura consumida por las élites y, a la vez, el japonismo invadió la decoración de interiores, la arquitectura, el diseño y el teatro. Mientras,

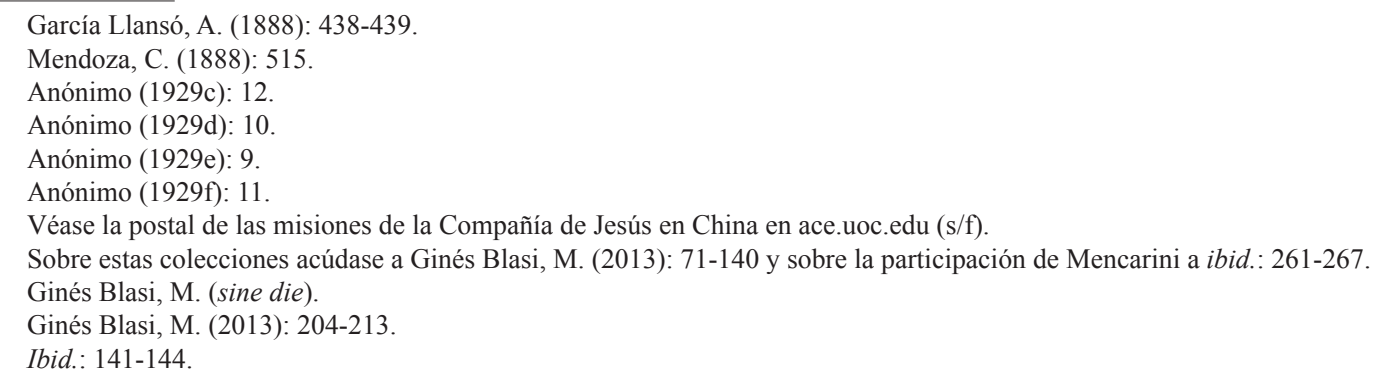


lo chino fue disfrutado por el gran público porque resultaba familiar, aunque su popularidad fue más restringida en las altas esferas y se limitó al coleccionismo. Este hecho queda perfectamente ejemplificado en tres locales de temática oriental abiertos en los años 30: Dancing Oshima, Dancing Wu Li Chang y en algunos elementos de la última reforma del cabaret La Criolla. El primero, a la moda japonesa, destinado a la burguesía y los dos últimos orientados a dar cobijo a las clases populares -uno de ambientación chinesca y el otro con ornatos japoneses eclécticos-.

\section{Dancing Oshima (1935-1938), un salón japonés para la aristocracia barcelonesa}

Debido a la impronta del japonismo en la ciudad, no resulta extraño que los empresarios abrieran locales de ocio que supieran explotarlo como forma de atracción. En una de las zonas más ricas de Barcelona, donde el paseo de Gracia se encuentra con la Gran Vía y la rambla de Cataluña, se emplazaba Oshima. Este salón de baile de aires japoneses se localizaba en la planta superior de Casa Llibre ${ }^{38}$, ocupando lo que anteriormente había sido una terraza conocida como Roof Garden ${ }^{39}$. El nombre escogido para este nuevo espacio hacía referencia a una isla cercana a la ciudad de Tokio "famosa por sus encantos, que atraen a los marineros de los buques que pasaban cerca de ella" ofrecido en una de las crónicas de la inauguración, muestra un relato similar sobre la isla al de la película de carácter documental titulada The Girls from Oshima (1930). Pese al mal estado de la cinta, los intertítulos narran brevemente como los isleños - especialmente las mujeres- acogen a aquellos marineros que se refugian en ella tras sufrir las inclemencias del océano ${ }^{41}$.

Si hacemos caso a las descripciones de los periódicos catalanes, la ceremonia de apertura fue todo un éxito, pues coincidió con la nueva temporada social y musical de invierno y con el retorno vacacional de la aristocracia. Según los periodistas invitados al acto, acudieron los más destacados representantes de la burguesía barcelonesa, atraídos por un lugar de reunión nocturna que pretendía equipararse a otros existentes en las principales capitales europeas ${ }^{42}$.

Se referían a la multitud de locales de apariencia oriental que habían estado en activo entre la segunda mitad del siglo XIX y las primeras décadas del XX. Aunque por aquel entonces muchos de ellos ya llevaban tiempo cerrados o habían sufrido importantes reformas, podemos destacar algunos de los pioneros en la ciudad de París. Por ejemplo, la sala de conciertos y café Le Bataclan construida por Charles Duval, inaugurada en 1864, que contaba con una profusa decoración exterior a modo de pagoda ${ }^{43}$. Poco después se sumó el restaurante Pavillon Chinois de Enghien-les-Bains (1867), muy cerca de la capital francesa ${ }^{44}$. También contamos con casos posteriores en diferentes puntos de Europa que abarcan una gran variedad de tipologías arquitectónicas, como la entrada y algunos pabellones del zoo de Berlín (1899). A parte de estos espacios en los que lo oriental era protagonista, no debemos olvidar todos aquellos edificios art nouveau y art decó en los que, con afán ecléctico, se entremezclaban elementos de diferentes culturas. Ya en España, debemos nombrar el Gabinete Japonés del Café Inglés de Madrid (a. 1908) ${ }^{45}$ o la casa de Bruno Cuadros en Barcelona $(1883)^{46}$.

Sin embargo, si nos centramos en los espacios de sociabilidad burguesa de carácter nipón en nuestro país, el más llamativo es sin duda alguna el efímero Teatro Japonés (1901-1903). Fue fundado por el empresario teatral José Fernández en la calle de Alcalá al calor de diversas compañías teatrales japonesas en funcionamiento en París con motivo de la Exposición Universal de 1900. Su magnífica decoración fue concebida por José Arija Saiz con una estética totalmente japonesa, pero las obras y actuaciones musicales del cartel eran de origen francés ${ }^{47}$.

Lo mismo ocurrió con los actos de Oshima, que poco tenían que ver con su decoración oriental. La crónica que más detalles ofrece sobre la magnífica velada de apertura el cinco de octubre de 1935 es la publicada en el diario $L a$ Vanguardia:

El decorado de este salón de noche está inspirado en un ambiente nipón clásico. Y para darle mayor fuerza de realidad se veía deambular entre sus columnas a una muchacha vestida y peinada al estilo de aquel remoto imperio, la cual llevaba una pequeña cesta con productos que ofrecía a la concurrencia. En su tarea tenía un compañero, asiático auténtico, también vestido con ropas orientales. Y afuera, en la puerta de la escalera que lleva a este salón, un portero del remoto Oriente, con vestidura típica, anunciaba con su presencia el ambiente interno de "Oshima". En las primeras horas de la noche fueron acudiendo muchísimas personas; al salir de los teatros acudieron más,

\footnotetext{
38 En 1925, Guillermo Llibre había trasladado su antigua confitería desde la plaza de Cataluña hasta la Gran Vía, donde también se acomodó el restaurante Ribas, creando la Casa Llibre. El prestigio de ambos negocios, el lujo del nuevo establecimiento diseñado por Enric Sagnier y su privilegiada localización los convirtieron en el centro de la vida social aristocrática del momento. Véase Villar, P. (2013): 40.

39 Se da noticia de este antiguo espacio desaparecido en Anónimo (1935a): 2 y Anónimo (1935b): 2.

40 Anónimo (1935c): 11.

41 El audiovisual y su ficha técnica están disponibles en www.britishpathe.com (2019).

42 Comparación ofrecida en Anónimo (1935b): 2.

43 www.pop.culture.gouv.fr (2019a).

www.pop.culture.gouv.fr (2019b)

Soiza Reilly, J. J. (1908): 65-66.

Hernández-Cros, J. E. (1987): 360.

47 Véase Anónimo (1900a): 10-11; Anónimo (1900b): 2; Anónimo (1901): 13; Barreiro, J. (2005): 31-33; Cavía Naya, V. (2013): 60-66 y Lara, D. de (1900): 2 .
} 
quedando lleno el salón. Cantó y bailó la antes nombrada artista, "Granito", y tocaron dos orquestas, la "Marimba" y la de Rabassa. La fiesta acabó a hora avanzadísima ${ }^{48}$.

La decoración concebida por el pintor e interiorista Carles María Baró Escalante, al que encontramos activo artísticamente desde $1923^{49}$, fue uno de los elementos que más llamó la atención a los clientes ${ }^{50}$. La dirección del local se preocupó por elegir a una persona interesada y conocedora del arte y la cultura japonesa. A parte de su faceta como decorador, Baró atesoró una colección de abanicos antiguos valorada en dos millones de pesetas. Contaba con ejemplares de los siglos XVI al XIX, así como con piezas de porcelana china y japonesa, aunque su personalidad como coleccionista debía ser bastante impulsiva, pues su esposa aseguraba que "incluso guarda los billetes de tranvía" ${ }^{51}$.

El artista creó un ambiente que se intuía desde el exterior solo con admirar la fachada [fig. 3]. El recién estrenado primer piso lucía un cartel luminoso con el nombre del salón de baile y una ornamentación inspirada en paneles corredizos con imágenes de cerezos en flor, ofreciendo un gran contraste con las esculturas de bronce y la planta baja concebida por Enric Sagnier en estilo clasicista, que es lo poco que se conserva del edificio original actualmente. La entrada estaba enmarcada por un torii y en el interior se repetía la decoración de paneles, haciendo también referencia a biombos pintados con elegantes paisajes boscosos y montañosos ejecutados con apenas unos trazos. Los pilares se aprovecharon para crear una falsa estructura de vigas, decorada con ideogramas, de la que pendían gran cantidad de farolillos. El espacio se organizó entorno a una pista de baile central, alrededor de la cual se colocaron gran cantidad de mesas bajas que, según la prensa, eran los muebles que más carácter japonés daban a Oshima ${ }^{52}$. En un lateral se situaba el escenario, donde se amenizaban las veladas con espectáculos de baile y musicales [figs. 4 y 5].

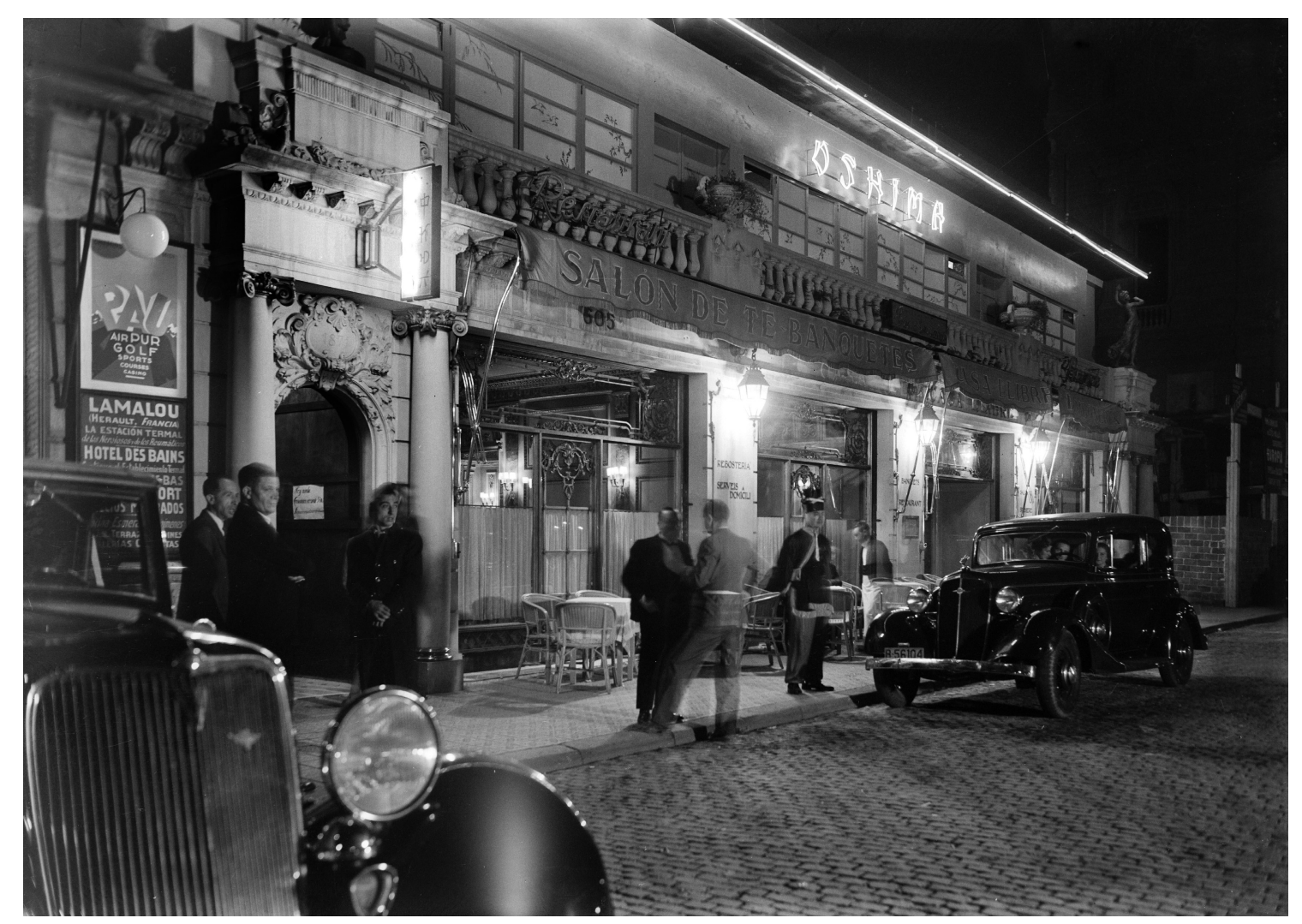

Fig. 3. Gabriel Casas i Galobardes, fachada de Casa Llibre, Arxiu Nacional de Catalunya, ANC1-5-N-2081.

\footnotetext{
Anónimo (1935c): 11.

49 La primera noticia que encontramos sobre su carrera artística es una exposición monográfica celebrada en el año 1923 dentro del salón de Bellas Artes "El Siglo". Véase Fontbona de Vallescar, F. (1999): 42.

50 Anónimo (1935d): 20.

51 La magnitud de su colección era tal que en el 1955 el Fomento de las Artes Decorativas de Barcelona organizó una serie de muestras monográficas con una exhibición titulada "El abanico a través de los siglos". En la cúpula del teatro Coliseum se mostraron doscientas de sus piezas al público por primera vez, con una buena representación de abanicos orientales. De hecho, en la vitrina central se encontraba "una de las piezas capitales [...] el abanico del siglo XVI en marfil calado y lacado, acaso uno de los primeros ejemplares llegados a España por la antigua ruta de Asia", que también ilustraba el cartel que anunciaba la exposición. Véase Anónimo (1955a): 16; Anónimo (1955b): 15; Baró Escalante, C. M. (1955) y Baró Escalante, C. M. / Escoda, J. (1957)

52 Anónimo (1935e): 13.
} 


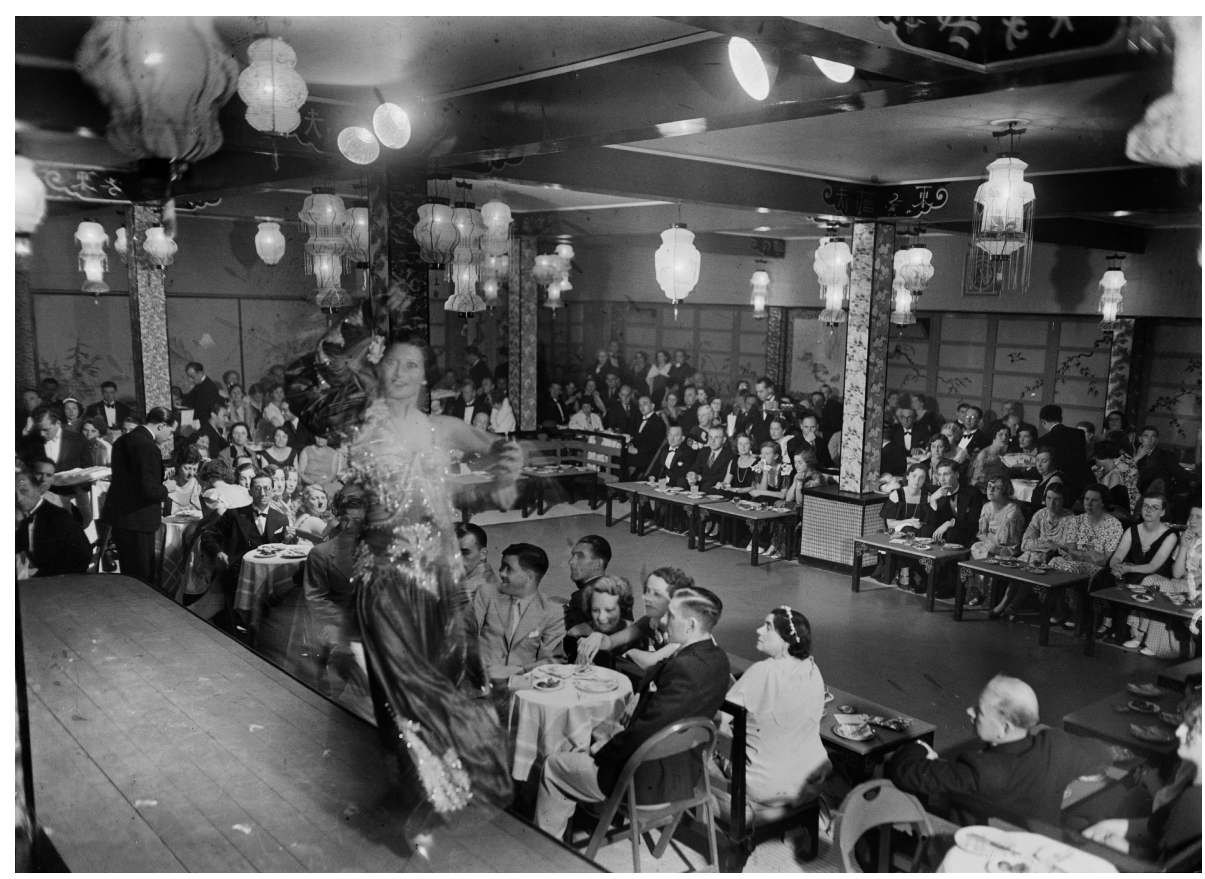

Fig. 4. Gabriel Casas i Galobardes, interior de Dancing Oshima, Arxiu Nacional de Catalunya, ANC1-5-N-2082.

Para reforzar la ambientación de la sala, las bailarinas y el personal femenino vestían kimonos y otras prendas inspiradas en atuendos orientales [fig. 6]. En ocasiones, eran los propios músicos los que se animaban a mimetizarse con la decoración del dancing, por ejemplo, en la primera actuación de Los 16 Artistas Reunidos, los "miembros vestían unas llamativas blusas de color (amarillo, encarnado, verde o azul), muy en consonancia con el ambiente del salón" 53 . Sin embargo, otras veces se acogían fiestas de temática diversa, como la organizada en honor de los cuatrocientos turistas del crucero inglés Montcare, lo que por otra parte nos da una idea aproximada de la gran capacidad de las instalaciones, con más salas de las que actualmente conocemos por fotografías. El 23 de octubre de 1935 se decidió celebrar una fiesta "de ambiente español [...] que consistió en 'canzonetas' y bailes regionales españoles, que a los ingleses gustaron sobremanera", además "las damas fueron obsequiadas con diversos objetos de arte de estilo japonés y español" 54 .

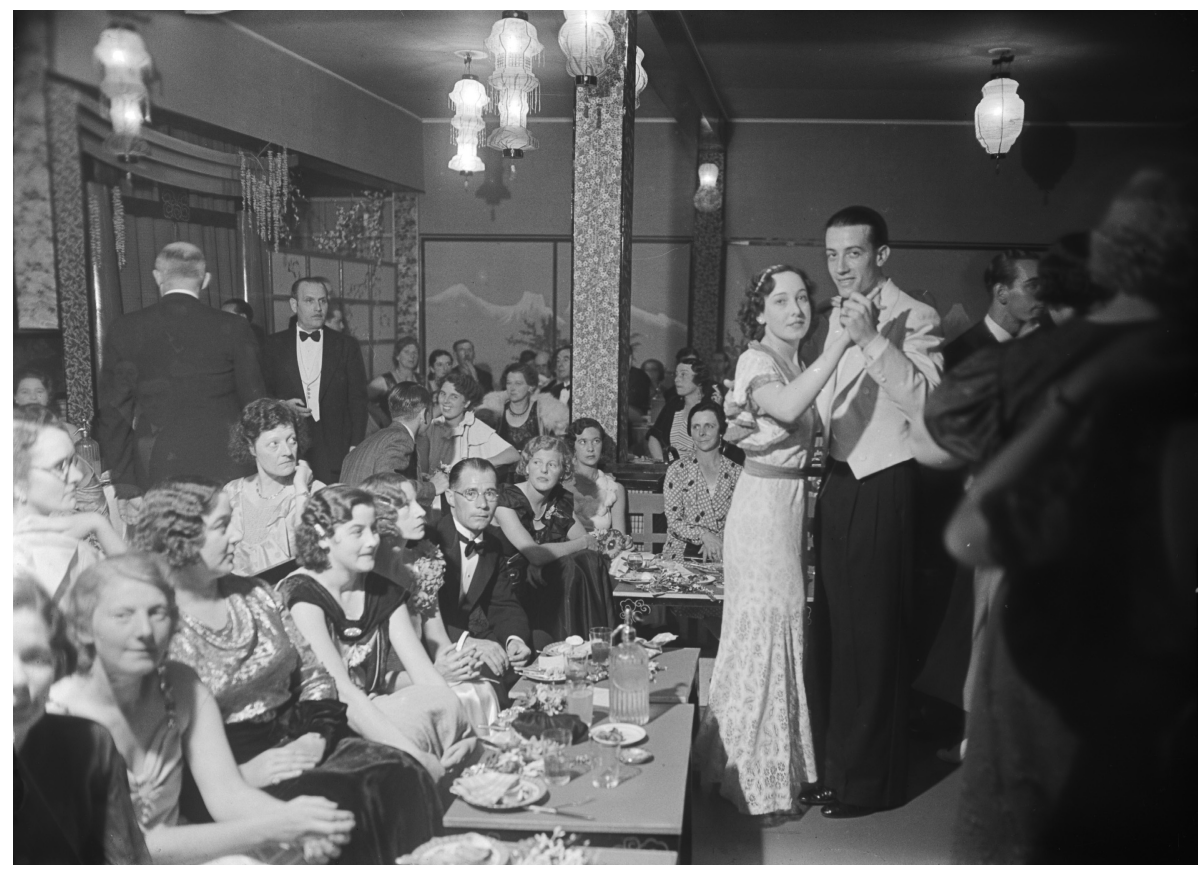

Fig. 5. Gabriel Casas i Galobardes, interior de Dancing Oshima, Arxiu Nacional de Catalunya, ANC1-5-N-2083.

53 Este concierto fue anunciado a página completa en el número de octubre-noviembre de 1935 de la revista especializada Jazz Magazine. Celebrado el seis de noviembre, fue una excepcional carta de presentación tanto para Los 16 Artistas Reunidos como para Oshima, que hacía apenas un mes que había abierto sus puertas. Esta banda de jazz fue la que mejores críticas recibió de cuantas actuaron en el local. Véase ibid. y Oliveres, C. (1935): 5.

54 Anónimo (1935f): 9. 


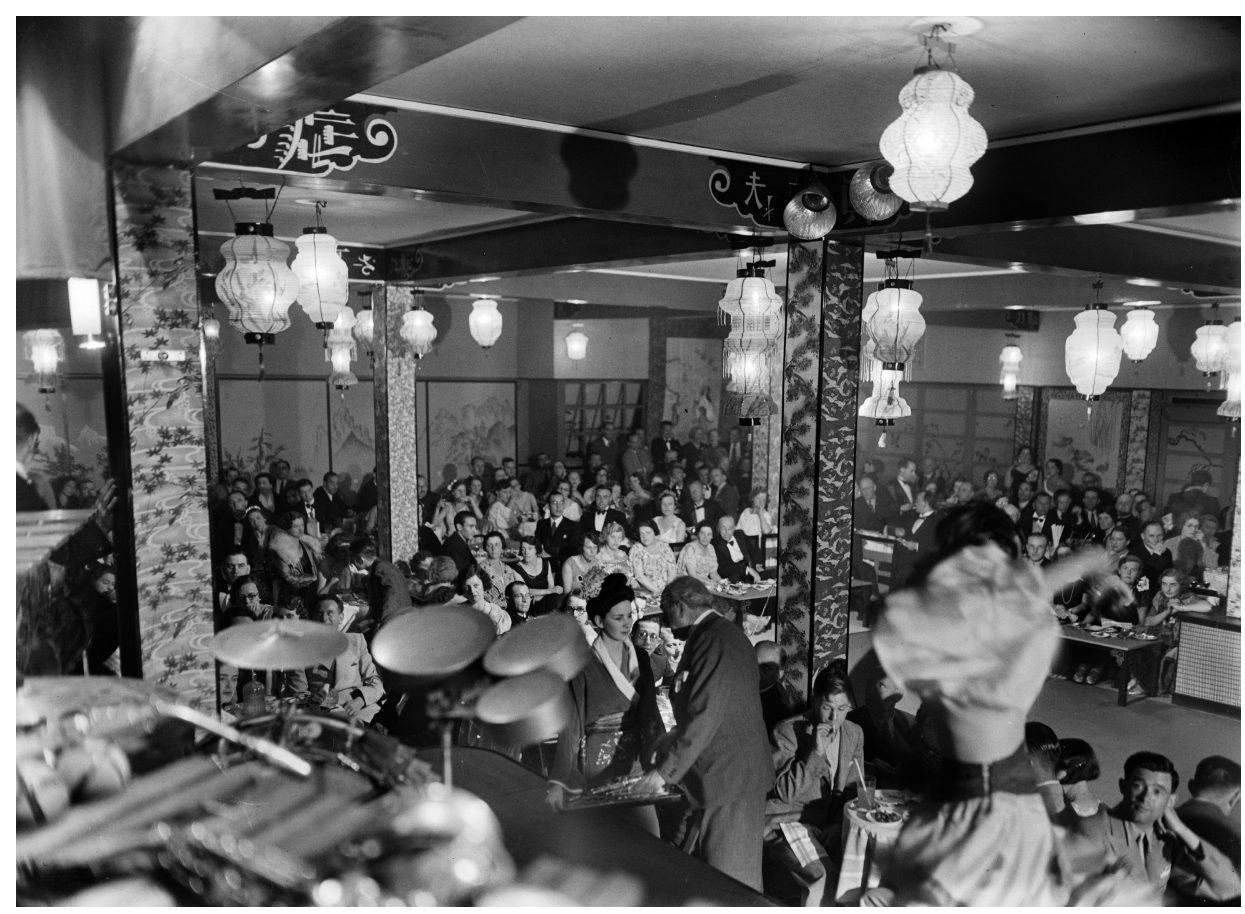

Fig. 6. Gabriel Casas i Galobardes, interior de Dancing Oshima, Arxiu Nacional de Catalunya, ANC1-5-N-2084.

En cuanto a los conciertos, que se ofrecían casi diariamente, la prensa catalana muestra anuncios de un variado cartel con diversas orquestas, pero especializado en grupos de jazz o música hot, como Bel Simphonic Boys, Crazy Boys Orchestra, Jaime Planas y sus Discos Vivientes, Marimba Salvadoreña y su animadora Granito de Sal, Demons Jazz o los ya mencionados Los 16 Artistas Reunidos, cabezas de cartel que hacían los deleites de los asistentes ${ }^{55}$. Incluso acudieron músicos de talla internacional como los afroamericanos Benny Carter o Juice Wilson que, tras una jornada musical de gran éxito en el teatro Coliseum, se arrancaron a improvisar en el cercano local japonés en una fiesta dedicada en su honor, una celebración que se alargó durante muchas horas ${ }^{56}$.

Por último, la dirección de Casa Llibre también organizó en su salón oriental tés selectos al atardecer, exclusivas fiestas de fin de año, conciertos radiados, "cock-tails dansants" para la facultad de Medicina y actuaciones de bailes de salón ${ }^{57}$. Sin embargo, el dancing era especialmente popular por su animación nocturna, que acogía a los personajes más destacados de la sociedad barcelonesa tras los eventos vespertinos. De hecho, se anunciaron las veladas a página completa en el programa oficial del teatro del Liceo para la temporada invernal de 1935-1936 con la frase "el sitio de reunión chic de Barcelona a las salidas de cines y teatros" [fig. 7].

\section{CASA LLIBRE}

EN LOS SALONES DE LA PLANTA BAJA, TODAS LAS TARDES A LA HORA DEL TÉ, REUNION DE NUESTRA SOCIEDAD MAS DISTINGUIDA:

BODAS B BANOUETES Y FIESTAS RESTAURANT - BAR - GRILL

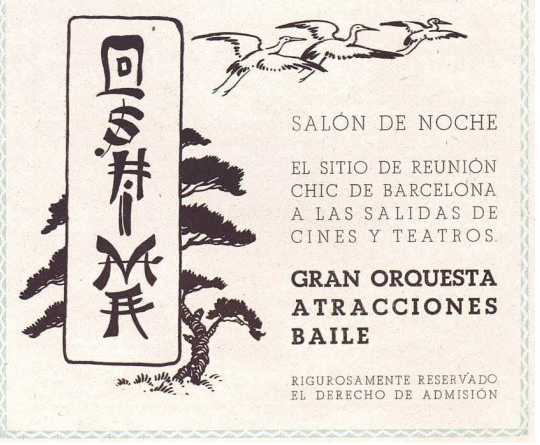

Fig. 7. Anónimo, programa oficial del Gran Teatro del Liceo de Barcelona, temporada de invierno 1935-1936, p. 34, Archivo Histórico de la Sociedad del Gran Teatro del Liceo de Barcelona.

Ibid; Anónimo (1935g): 10; Anónimo (1936a): 7 y Anónimo (1937a): 7.

6 Anónimo (1936b): 10 y García, J. (2012): 31.

57 Anónimo (1935h): 10, Anónimo (1935i): 14, Anónimo (1935j): 8, Anónimo (1935k): 13, Anónimo (19351): 10, Anónimo (1936c): 12 y Anónimo (1936d): 20 . 
Además, en ocasiones, las entradas de algunos pases de cine servían para asistir a las fiestas de estreno de las mismas películas. Especialmente sonado fue el baile de gala celebrado el nueve de noviembre de 1935 con motivo de la première de La Viuda Alegre en el cine Fèmina. El espectáculo se inspiró en la época de la cinta, pero sonaron canciones de jazz, vals y otros géneros de lo más variado hasta las cuatro de la madrugada ${ }^{58}$.

\section{Dos cabarets del Barrio Chino con aroma al Lejano Oriente: Dancing Wu Li Chang (1932-1938) y La Criolla (1925-1938)}

Como ya hemos señalado, la presencia de la cultura china tuvo su mayor incidencia en la ciudad a finales del siglo XIX, minimizándose en contraposición a la japonesa a inicios del XX, repuntando nuevamente en los años 30. Dicha existencia estuvo ligada a la aparición de artículos y revistas sobre su cultura, al coleccionismo de objetos artísticos, textiles y numismáticos, trajes, escenarios arquitectónicos y en la temática de festivales, como advertimos en el "arco-pagoda" que decoraba la calle de la Boquería en la fiesta de la Mercè de 1902 [fig. 8], o en el ornato de una carroza del carnaval de Barcelona del año 1934 [fig. 9]. Este influjo chinesco también llegó a manifestarse en la decoración de establecimientos como el Dancing Wu Li Chang.

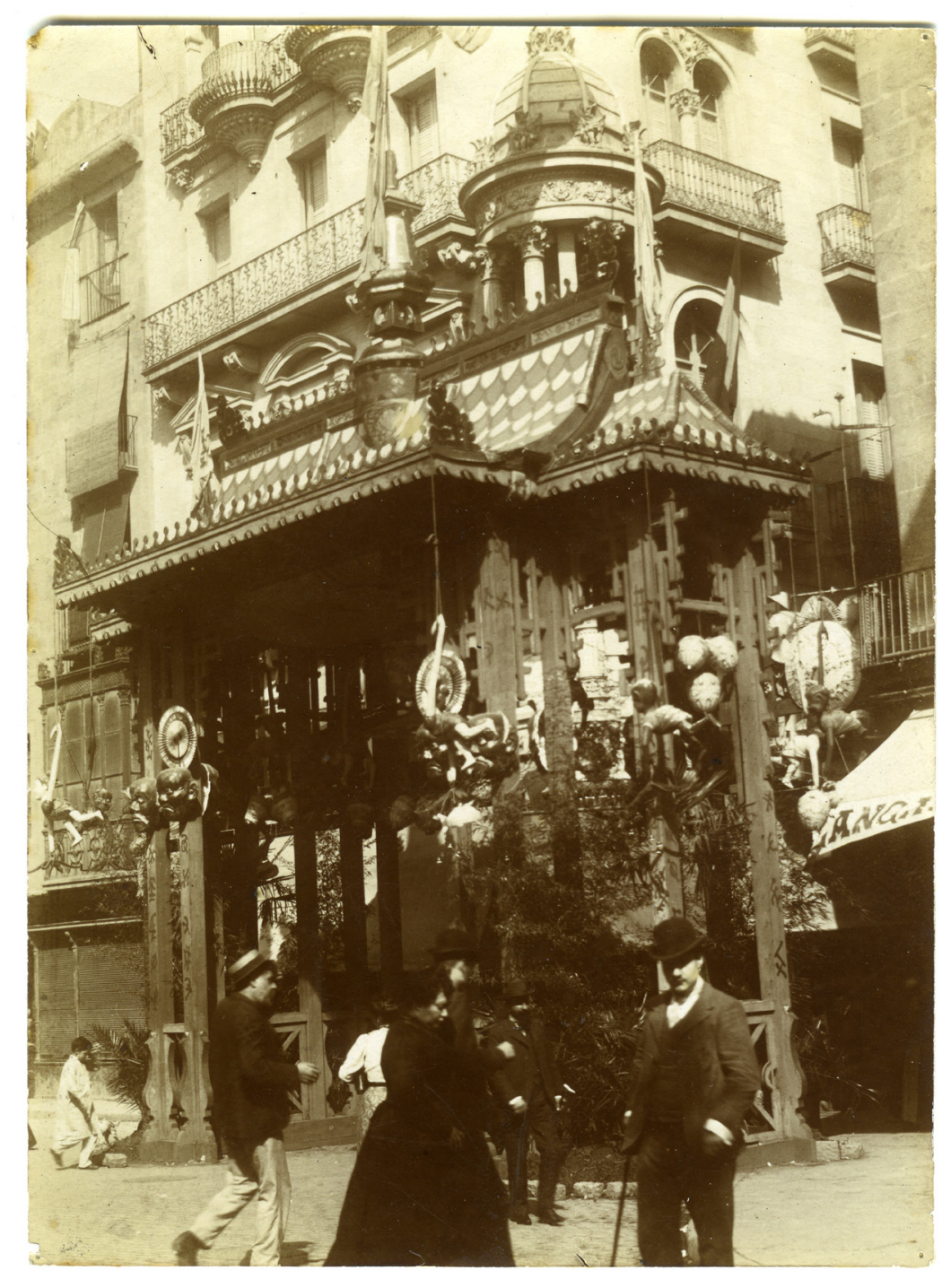

Fig. 8. Frederic Ballell Maymí, arco-pagoda de inspiración china de la calle de la Boqueria, 01/09/1902-30/09/1902, Arxiu Fotogràfic de Barcelona, AFB3-117 Editorial López.

Este music-hall se ubicó en la calle del Cid no 7 , en la zona marginal de la ciudad, el Distrito V, actualmente conocido como el Raval y rebautizado a inicios del siglo XX con el nombre de "Barrio Chino". Este calificativo lo acuñó por vez primera el periodista Francisco Madrid en el año 1925 para designar a un espacio comprendido entre

58 Anónimo (1935m): 22, Anónimo (1935n): 24 y Anónimo (1935ñ): 7. 
el puerto, la calle Conde del Asalto -actual Nou de la Rambla-, la Rambla y el Paralelo ${ }^{59}$, con unas connotaciones negativas, entendido como "un terrible foco de infección, domicilio de la mala gente y los bajos fondos, una zona

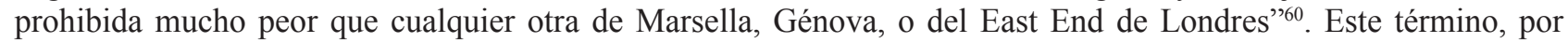
tanto, no estuvo relacionado con la existencia de un nutrido grupo de inmigrantes orientales establecidos en dicho espacio, aunque sí se ha podido documentar la existencia de ocho vendedores ambulantes asiáticos en $1930^{61}$. El vocablo empleado por el periodista reflejaba una serie de rasgos perniciosos que, en el imaginario colectivo, llevaban implícitos los chinatowns americanos, percibidos como lugares de desorden público, crímenes, terror y libertinaje.

Debido a la masificación que supuso la reindustrialización de los años 20, la sociedad demandante de ocio y vida nocturna quedaba satisfecha con la cantidad de tabernas, cabarets y dancings; donde el alcohol, las drogas, las reyertas y la prostitución estaban presentes diariamente hasta altas horas de la madrugada. Ese ambiente libertino y de mezcolanza de gentes, en el que todo valía, lo convirtió en atractivo para un amplio público, en el que podían encontrarse tanto las clases más desfavorecidas de la ciudad, como los burgueses locales y turistas internacionales que lo concibieron como un vicioso barrio de recreo, como la "París del Sur". Su desenfreno y pluralidad eran únicos en el mundo, como bien expresó el actor americano Douglas Fairbanks "hijo": "No he vist mai en la vida una cosa semblant; ni a Saigón, ni a Xanghai, ni a Port-Said... enlloc!" 62 . El periodista Gabriel Trillas Blázquez añadía que, "para completar el mito del libertinaje, ¡cómo había de faltar un Wu Li Chang en el barrio Chino!”63.

El nombre de este local deriva de una popular obra trágica de teatro británica de 1919, traducida y adaptada al castellano por Federico Reparaz en 1928. Fue representada en numerosas plateas de todo el territorio español y las Américas por la compañía del actor Ernesto Vilches ${ }^{64}$. De ella se rodaron dos versiones cinematográficas ${ }^{65}$, una estadounidense y otra española, que la convirtieron en un icono de la cultura popular [figs. 10 y 11$]^{66}$.

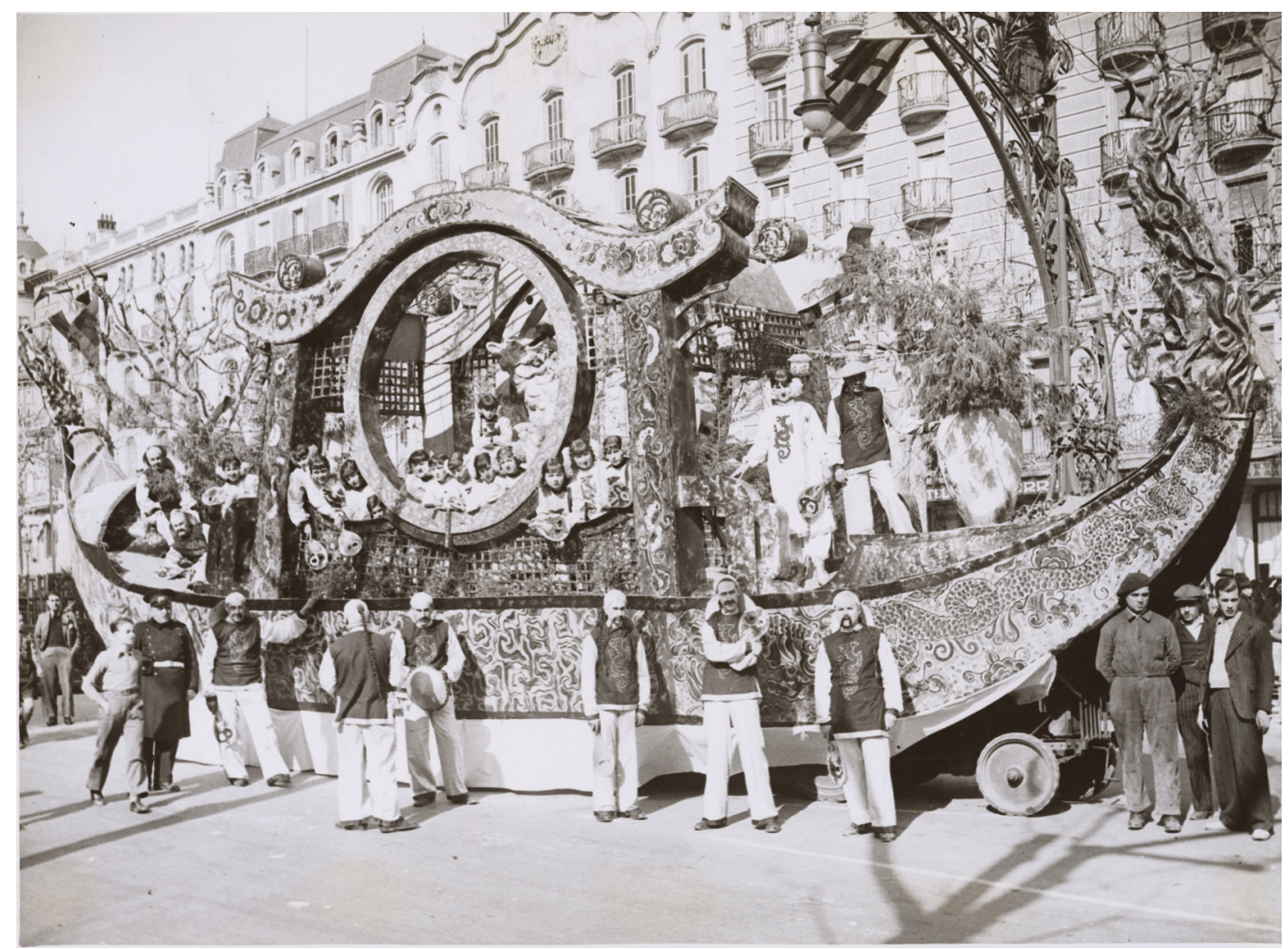

Fig. 9. Carlos Pérez de Rozas, paso de una carroza por el paseo de Gracia para el carnaval de Barcelona, 11/02/1934-11/02/1934, Arxiu Fotogràfic de Barcelona, L100 Cultura.

\footnotetext{
Fernández González, M. (2012): 308.

Ealham, C. (2007): 57.

Alavedra, J. (1930): 2.

Tomás, J. (1934): 4.

Trillas Blázquez, G. (1935): s.n.

4 Anónimo (1919): 6.

65 De hecho, la adaptación española de la película fue una de las primeras iniciativas en la que se acogió a actores nacionales en Hollywood. Véase Donovan, M. K. (2016): 22 y Cerón Gómez, J. F. / Martínez González, J. (1999): 114-115.

${ }_{66}$ Recibió una amplísima cobertura en los medios especializados y, una vez estrenada, en los principales periódicos del país. Para comprobar su repercusión seleccionamos las siguientes notas de prensa: Anónimo (1930a): 11, Anónimo (1930b): 12, Anónimo (1930c): 21, Anónimo (1931a): 15, Anónimo (1931b): 15-16, Anónimo (1931c): 14, Anónimo (1931d): 15 y Anónimo (1931e): 12.
} 
Su apertura se llevó a cabo a inicios de los años 30, cuando Antonio Sacristán Collado (1872-1939) ${ }^{67}$ decidió reformar una de sus dos salas de baile del barrio chino, Ca'l Sagristà -abierta a mediados de la década de los años $20-$, y convertirla en un establecimiento con aire chinesco. Tal renovación se produjo "de cara al turista i a la gent adinerada de l'Eixampla", buscando ampliar el negocio ${ }^{68}$. No conocemos la fecha exacta de la inauguración del establecimiento, si bien, tenemos constancia de que el 1 de abril de 1932 aún se anunciaba como "Internacional Sagristà"69 [fig. 12], mientras que el 26 de mayo del mismo año, en un artículo periodístico titulado "Reformes illògiques", ya se reflejaba esta reforma ${ }^{70}$ :

Abans, aquest famós bar del carrer del Cid [Ca'l Sagristà] tenia tot l'aire d'un salón de port anglès. Plafons ingenus a les parets, damunt els quals el pinzell tremolós d'algún decorador de diumenge havia traçat uns vapors d'estampa colonial i uns paisatges tropicals de capsa de panses o d'havans. Ara, tot allò tan ple de candor i de caràcter ha estat substituit per un groc insolent que ha envait totes les parets, damunt el qual un pintor massa traçut ha dibuxat unes fantasies xineses detestables ${ }^{71}$.

Fig. 10. Anónimo, anuncio de Wu Li Chang, publicidad sobre la exitosa película protagonizada por Ernesto Vilches, La Libertad, Madrid, 12/02/1931, p. 10.
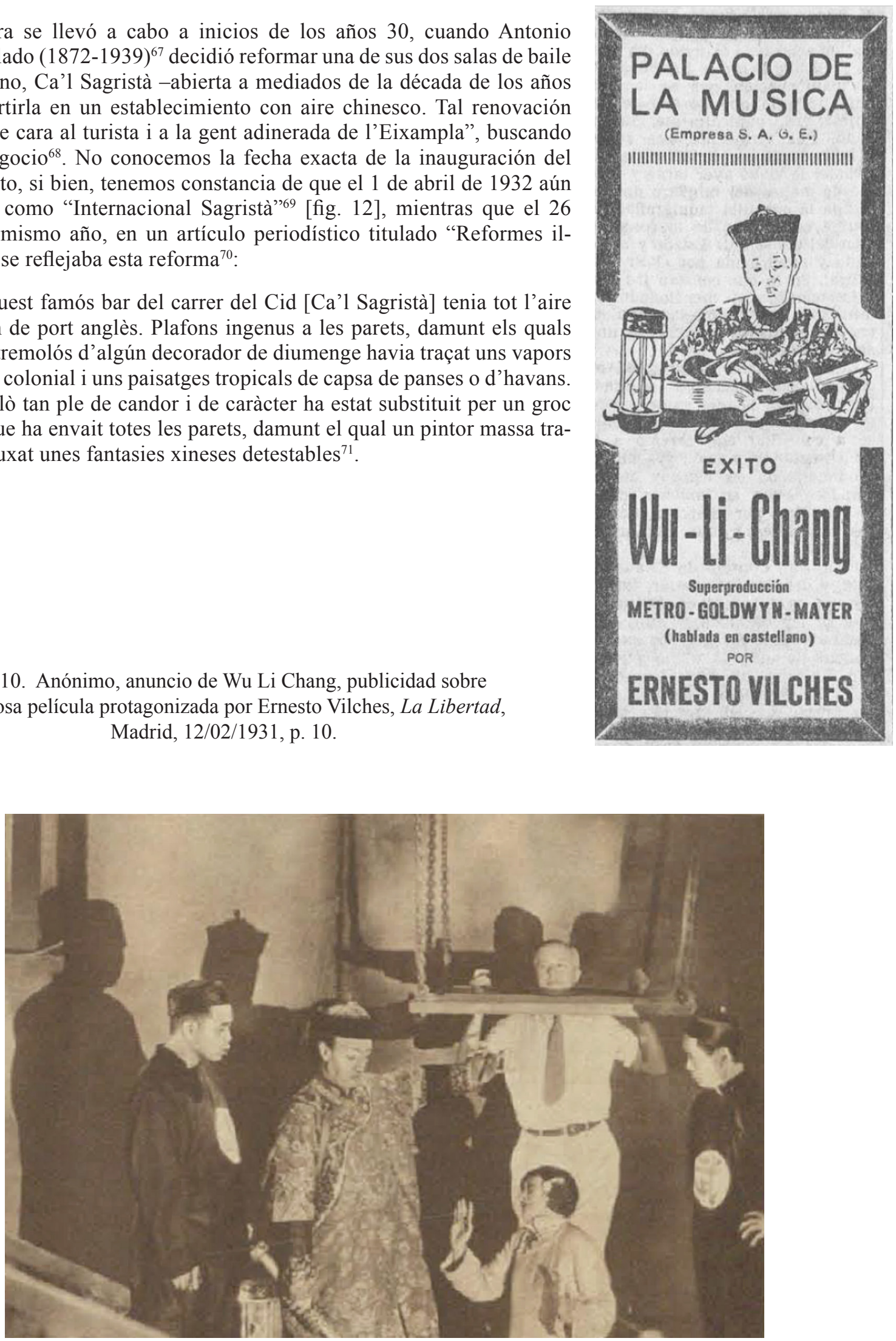

Fig. 11. Anónimo, descanso durante el rodaje de la película Wu Li Chang con Ernesto Vilches como protagonista, Cinegramas, Madrid, 21/04/1935, p. 7.

\footnotetext{
67 Anónimo (1939): 2. Sabemos que el 25/09/1939 murió a la edad de 67 años, siendo marido de Da Ramona Alegre Salvador y padre de María, Antonio, Nemesio, Anita y Amparo.

68 Gasch, S. (1932): 9.

69 Anónimo (1932): 14

70 Hasta este momento se pensaba que se había realizado en 1934. Véase Donovan, M. K. (2016): 22.

71 Gasch, S. (1932): 9.
} 
Formalmente, se trataba de un espacio diáfano, muy austero, pintado completamente de amarillo, color asociado con el emperador, aunque también pudiera hacer referencia al peligro amarillo, un falso tópico de la época que sugería connotaciones negativas de retraso, falta de salubridad o vandalismo asociadas a la inmigración china. El centro del local lo ocupaba un escenario cuadrangular sobre el que se sucedían las actuaciones, alrededor del cual se congregaba el público, reunido entorno a pequeñas mesas circulares. El espacio se organizaba por medio de una serie de pilares cuadrangulares adornados con reproducciones del nombre del local y diversos sinogramas [fig. 13] que corrieron a cargo del popular ilustrador tarraconense Ricard Opisso (Tarragona, 1880-Barcelona, 1966) ${ }^{72}$. Este artista se dio a conocer con sus dibujos satíricos de la revista L'Esquella de la Torratxa, consiguiendo auparse, por su estilo, a la vanguardia de la ilustración europea $^{73}$.

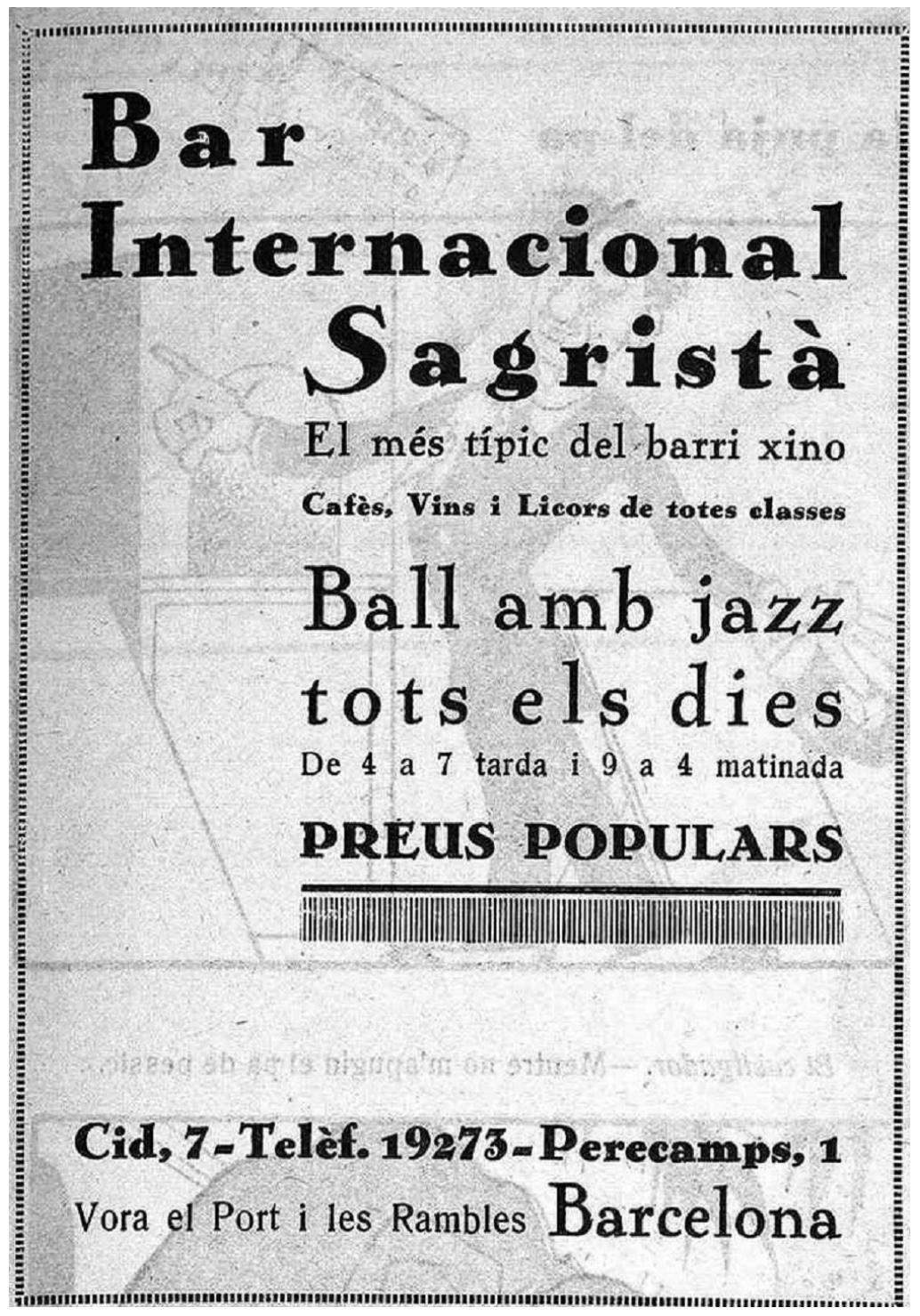

Fig. 12. Anónimo, anuncio del Bar Internacional Sagristà, L'Esquella de la Torratxa: periódich satírich, humoristich, ilustrat y literari, Barcelona, 01/04/1932, p. 14.

La popularidad del local estaba vinculada a los nocturnos y recurrentes números de transformistas, como la popular gallega Mirko [fig. 14], ataviadas con indumentaria de aire chinesco, para armonizar con la decoración. Estos espectáculos se llenaban diariamente con una amplia clientela, desde obreros y marineros hasta personajes famosos de la talla del ilustre boxeador Marcel Thil ${ }^{74}$, las actrices Catalina Bárcena y Paulina Singerman, o escritor Gregorio Martínez Sierra ${ }^{75}$. Frecuentemente, se les ofrecían sombreros dǒuli para ambientar el show. [fig. 15]

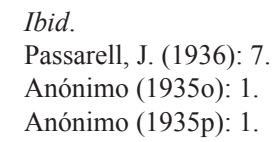




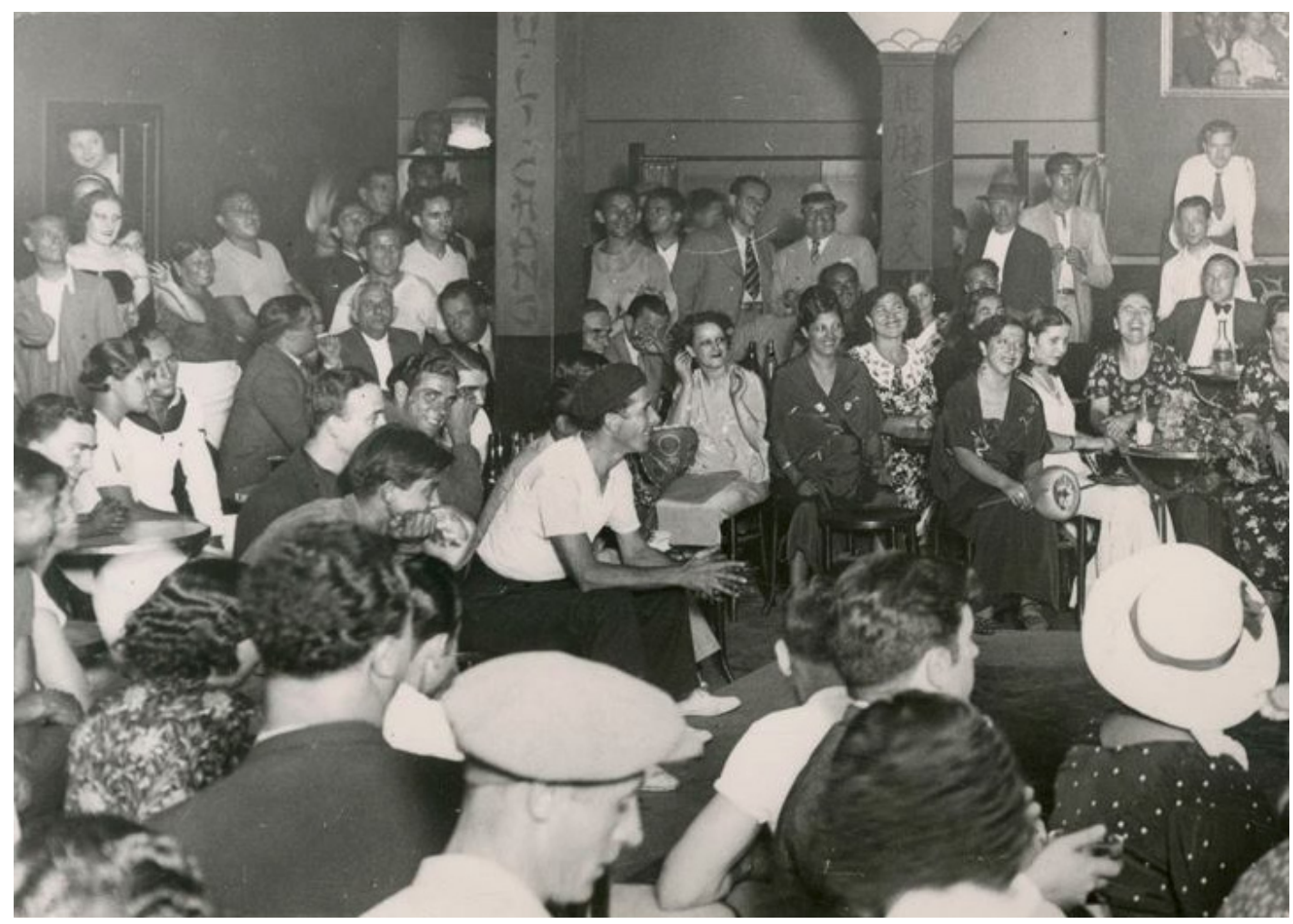

Fig. 13: Anónimo, interior de Wu Li Chang, en Barcelonauta, Miquel (2010): Wu-Li-Chang. Dancing Cabaret. (1934-1938) [página WEB], bar.cel.ona.uta.

http://barcelofilia.blogspot.com/2010/11/wu-li-chang-dancing-cabaret-1934-1938.html [Consulta: 30/01/2020].

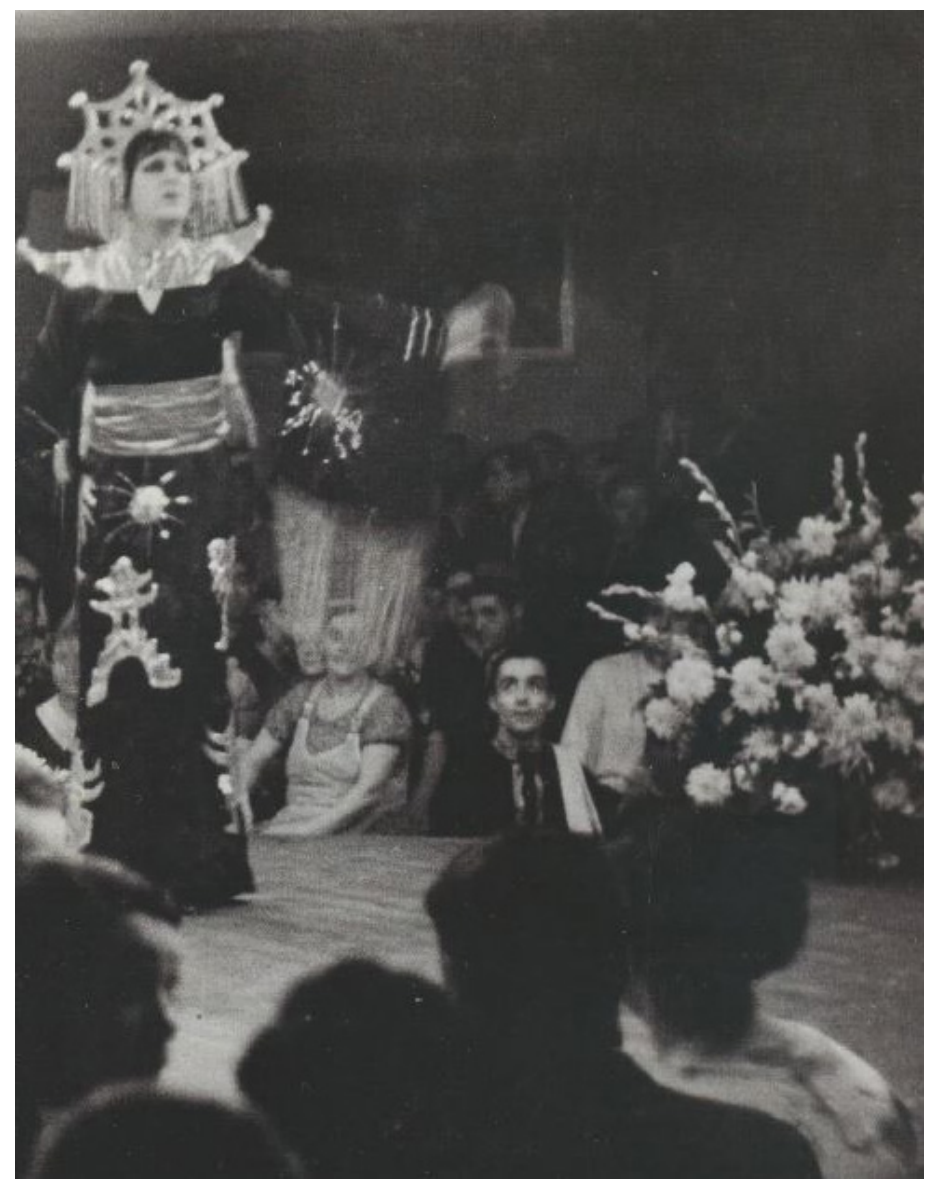

Fig. 14. Anónimo, Mirko actuando en Wu Li Chang, en Barcelonauta, Miquel (2010): Wu-Li-Chang. Dancing Cabaret. (1934-1938) [página WEB], bar.cel.ona.uta.

http://barcelofilia.blogspot.com/2010/11/wu-li-chang-dancing-cabaret-1934-1938.html [Consulta: 30/01/2020]. 


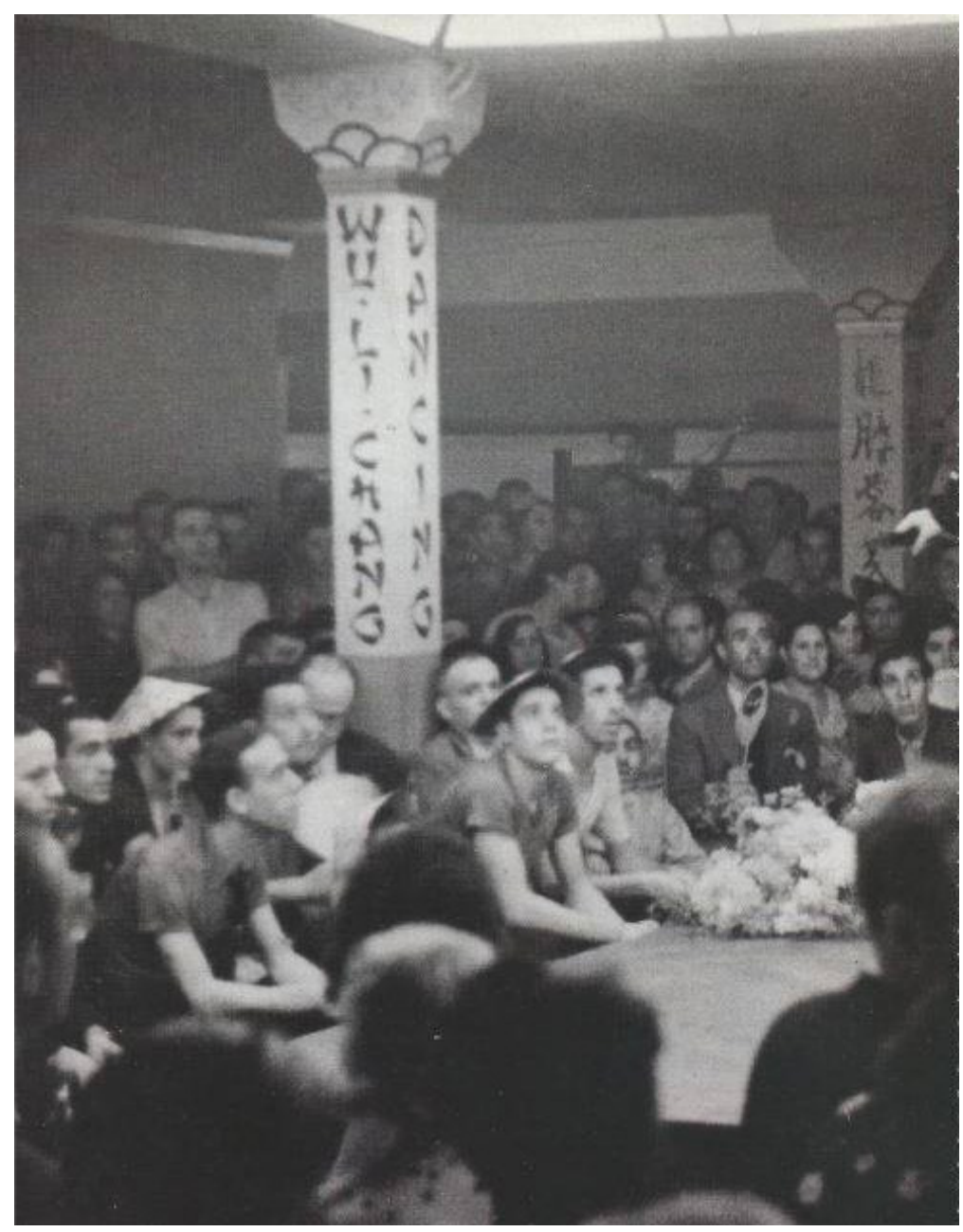

Fig. 15. Anónimo, asistentes a un espectáculo en Wu Li Chang, en Barcelonauta, Miquel (2010): Wu-Li-Chang. Dancing Cabaret. (1934-1938) [página WEB], bar.cel.ona.uta.

http://barcelofilia.blogspot.com/2010/11/wu-li-chang-dancing-cabaret-1934-1938.html [Consulta: 30/01/2020].

Enfrente de este establecimiento, en el n. ${ }^{\circ}$ 10, se anunciaba el que fuera el cabaret más famoso de la ciudad, La Criolla, con un llamativo cartel rojo de neón de tres pisos de altura ${ }^{76}$. Se trataba del otro dancing que poseía Antonio Sacristán Collado, en este caso en colaboración con Valentín Gabarró. En sus más de diez años de vida (1925-ca. 1938), buscando una mayor atracción ciudadana, se llevaron a cabo diversas reformas, de las que al menos 3 se produjeron en la década de los 30. En una de ellas, aunque no de un modo tan imperante como en los ejemplos ya comentados, se optó por insertar algún elemento decorativo japonés.

Desafortunadamente, no poseemos fotografías que evidencien dicho cambio y todo lo que nos queda del mismo se resume en una noticia periodística que refleja la reforma ya mencionada. En él se indica que aquel local decorado con unas "palmeres d'un verd brutal" había pasado a estar ocupado por "un porter galonat [...], unes cambrers vestits de verd de regadora, uns músics amb ulleres de carei i un negre amb smoking colonial [...], gent disfressada damunt unes parets plenes de purpurina daurada". Esta renovación no debió ser muy aclamada, dado que era recurrente en todos los dancings del país y los turistas buscaban en el Chino otros reclamos. Por ello, se llevó a cabo su última transformación en la que se instalaron unos "fanalets japonesos":

I s'han apressat a tapar aquelles vergonyes [...]. I darrerament ho han guarnit amb fanalets japonesos $i$ uns grans fanals amb escenes del XVIII sobre una imitació de pergami pintat, amb emparrats de floretes d'ametller artificials i serrells de paper verd. Naturalment, tot això d'ara és un magnific farrigo-farrago, és la decoració més incoherent que us pugueu imaginar ${ }^{77}$.

\footnotetext{
76 "A la part de fora de l'establiment hi ha un castell lluminós que és una meravella. Agafa tota la façada uns tres pisos de dalt a baix. Unes grand lletres vermelles, que diuen LA CRIOLLA. El carrer del Cid, generalment, és mal illuminat. Així és que la resplandor de l'anunci del famós bar agafa un prestigi excepcional. Tot el carrer queda tenyit d'una capa de vermellor que li dóna un to fantàsticament irreal. Dirieu que se tracta d'un gran true d'escenografia. El personal que circula per la calçada i els invertits i les prostitutes que s'eshibeixen per les voreres, participen d'aquest bany de vermell brut i queden decoratius, estilizats, com les illustracions que deu somiar Francis Carco per als seus llibres”. Planes, J. M. (1929): 2.

77 Gasch, S. (1932): 9.
} 


\section{Conclusión}

Estos tres dancings son ejemplos de cómo los diferentes grupos sociales disfrutaban de la fervorosa vida nocturna que la Ciudad Condal ofreció durante los años 30. Por una parte, el salón japonés abierto frente a los jardines de la Reina Victoria se convirtió en uno de los puntos de encuentro de la burguesía catalana. Allí celebraba sus banquetes y fiestas alejada de la conflictividad social que caracteriza a este periodo. Mientras, en el otro extremo de la ciudad un ruido atronador y grandes bocanadas de humo salían de las tabernas cercanas al puerto. En Wu Li Chang y La Criolla, como en el resto de los bares y salas de baile cercanas, el público era mucho más heterogéneo. En este barrio se divertían todos aquellos que no podían acceder a las celebraciones de los más adinerados. Además, con el tiempo se sumaron aquellos curiosos aristócratas y artistas que bajaron la Rambla cansados de la corrección de la esfera burguesa y deseosos de vivir aquel ambiente al margen de la ley y de lo socialmente aceptado. Fiestas de renombre, frecuentadas por periodistas que redactaban crónicas, y espectáculos anónimos, sucedían a la misma hora y en la misma ciudad, pero siempre fueron realidades ajenas. Poco menos de un kilómetro de distancia, pero dos mundos a las antípodas.

De todos modos, podemos trazar un paralelismo claro entre los dos negocios. La presencia de lo oriental en ambos actuaba como una mera carcasa que les diferenciaba, por su exotismo, de sus más cercanos competidores. En Oshima, el ambiente nipón respondía a la oleada japonista que había recorrido el Viejo Continente y que en esa década estaba mostrando sus últimas manifestaciones. Los clientes estaban encantados, como recogen las propias crónicas, de acudir a un espacio que les permitía ponerse al nivel de otras capitales europeas. Igualmente, la temática oriental ecléctica de los dancings de Antonio Sacristán tenía como única finalidad perpetuar el mito del Barrio Chino. Si bien en el primer caso podemos admitir que había un mayor conocimiento de la cultura oriental, en ambos lugares se llevaban a cabo prácticas meramente occidentales como conciertos de jazz, lip syncs de divas patrias de la canción o incluso fiestas temáticas cercanas a la parodia.

No conocemos exactamente cuándo se cerraron las puertas de ninguno de estos locales, aunque en todos los casos su clausura está relacionada con el estallido de la Guerra Civil. En primer lugar, tenemos constancia de que en 1936, tras la prohibición de la Generalitat de Cataluña de los espectáculos de transformistas, se iniciaría el "període agònic" de los cabarets del Paralelo y, con ellos, también los del Barrio Chino ${ }^{78}$. Sabemos que los bares de la calle del Cid y tantos otros de la zona portuaria, entre los cuales se encontraban los aquí tratados, fueron destruidos el veinticuatro de septiembre de 1938 tras un bombardeo de la aviación italiana que, al final de la guerra, se llevaría por delante más de mil quinientos edificios. Su huella quedaría oculta por la reforma urbanística de la posguerra, que culminó en 1971 con la inauguración de una nueva avenida y un edificio de veinticinco plantas, mal recibido por los vecinos porque desfiguraba el aspecto original del barrio ${ }^{79}$.

En cuanto a Oshima, podemos seguirle la pista gracias a algunos periódicos que anunciaban sus eventos periódicamente. La última noticia que conocemos sobre el establecimiento es la cena y fiesta del fin de año de 1937 , que fue amenizada por la Rabassa Orchestra ${ }^{80}$. También tenemos constancia de la actividad de Casa Llibre hasta finales de la década de los 40, cuando se compró el solar para la construcción de un hotel que todavía sigue abierto. Las nuevas plantas del Avenida Palace fueron proyectadas por el hijo de Enric Sagnier, el arquitecto de la primigenia Casa Llibre, respetando la planta baja. Se inauguró en 1952, momento en el que pensamos que ya había desaparecido cualquier vestigio de la sala de baile japonesa ${ }^{81}$.

El conflicto bélico no solo se llevó consigo estos espacios, directa o indirectamente. También marcó el final del japonismo, que había teñido de multiculturalidad uno de los periodos más deslumbrantes de la historia de la ciudad de Barcelona. En el sistema nacionalcatólico que impondrían las nuevas élites solo tenía cabida lo genuinamente español: el academicismo y la estética herreriana del reinado de Felipe II.

\section{Bibliografía}

ace.uoc.edu (s/f): Postal del stand de las misiones jesuitas en el Palacio de las Misiones. Archivo China España 18001950. Universitat Oberta de Catalunya. http://ace.uoc.edu/items/show/180 [Consulta: 31/12/2019].

Alavedra, Joan (1930): "El «perill groc» a Barcelona", Mirador: setmanari de literatura, art i politica, Barcelona, 26/06/1930, p. 2.

Almazán Tomás, David (2003): “La seducción de Oriente: de la chinoiserie al japonismo". En: Artigrama, 18, Zaragoza, pp. 83-106.

Almazán Tomás, David (2006): “Las exposiciones universales y la fascinación por el arte del Extremo Oriente en España: Japón y China”. En: Artigrama, 21, Zaragoza, pp. 85-104.

Anía Ruíz-Flores, Pablo César (2019): "La presencia de Hokusai en la prensa española (1868-1926): biografía, obra y valoración crítica". En: Mirai. Estudios Japoneses, 3, Madrid, pp. 145-165.

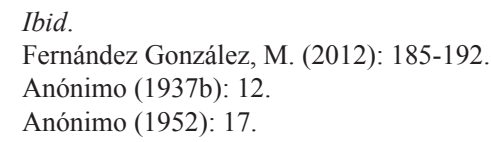


Anónimo (1888a): "Nuestros grabados. Yong-Heng, jefe de la sección china de la Exposición Universal de Barcelona", La Ilustración, Barcelona, 29/07/1888, p. 494.

Anónimo (1888b): “La Exposición Universal”, La Vanguardia, Barcelona, 11/04/1888, p. 2.

Anónimo (1892): "Servicios de la Compañía Trasatlántica de Barcelona”, Blanco y Negro, Madrid, 06/03/1892, p. 159.

Anónimo (1900a): “Actualidades, Teatro Japonés”, Vida Galante, Madrid, 07/10/1900, pp. 10-11.

Anónimo (1900b): “Teatro Japonés”, El Liberal, Madrid, 02/10/1900, p. 3.

Anónimo (1901): “Teatro Japonés”, Blanco y Negro, Madrid, 26/10/1901, p. 13.

Anónimo (1919): "Noticias é informaciones teatrales", La Correspondencia de España: diario universal de noticias, Madrid, 21/12/1919, p. 6.

Anónimo (1929a): “La Exposición Internacional. Inauguración de la Sección Japonesa”, La Vanguardia, Barcelona, 18/06/1929, p. 10.

Anónimo (1929b): "Inauguración de la sección japonesa", $A B C$, Madrid, 18/06/1929, p. 33.

Anónimo (1929c): “La inauguración de la Exposición Misional”, La Vanguardia, Barcelona, 09/06/1929, p. 12.

Anónimo (1929d): “El catolicismo en China”, La Vanguardia, Barcelona, 24/08/1929, p. 10.

Anónimo (1929e): “Inauguración del Palacio de las Misiones”, La Vanguardia, Barcelona, 30/06/1929, p. 9.

Anónimo (1929f): "Ecos de la Exposición. El Palacio de las Misiones”, La Vanguardia, Barcelona, 09/07/1929, p. 11.

Anónimo (1930a): "Vida cinematográfica. Dicen los astros... la opinión de Vilches", La Vanguardia, Barcelona, 07/08/1930, p. 11.

Anónimo (1930b): "Vida cinematográfica. Dicen los astros... Vilches en Hollywood”, La Vanguardia, Barcelona, 12/08/1930, p. 12.

Anónimo (1930c): “Ecos y noticias”, La Vanguardia, Barcelona, 23/09/1930, p. 21.

Anónimo (1931a): "Vida cinematográfica. Cosas de Hollywood”, La Vanguardia, Barcelona, 26/04/1931, pp. 14-15.

Anónimo (1931b): “Ecos y noticias”, La Vanguardia, Barcelona, 29/04/1931, pp. 14-16.

Anónimo (1931c): "Vida cinematográfica. Los estrenos: "Wu-li-Chang en el Femina", La Vanguardia, Barcelona, 06/05/1931, p. 14.

Anónimo (1931d): “Wu-li-Chang, Angelita Benítez-Ernesto Vilches”, ABC, Madrid, 18/02/1931, p. 15.

Anónimo (1931e): "Wu-li-Chang”, Films Selectos, Madrid, 25/04/1931, p. 12.

Anónimo (1932): “Anuncio”, La Esquella de la Torratxa: periódich satírich, humorístich, illustrat y literari, Barcelona, 01/04/1932, p. 14.

Anónimo (1935a): “Oshima, un nou saló de nit”, La Humanitat, Barcelona, 04/10/1935, p. 2.

Anónimo (1935b): “Oshima, nou saló de festes d'un entonat ambient cosmopolita”, La Humanitat, Barcelona, 08/10/1935, p. 2.

Anónimo (1935c): “Week end en Barcelona”, La Vanguardia, Barcelona, 08/10/1935, p. 11.

Anónimo (1935d): "Dissabte va inaugurar-se «Oshima»”, La Veu de Catalunya, Barcelona, 08/10/1935, p. 20.

Anónimo (1935e): "Una audición de «hot»", La Vanguardia, Barcelona, 16/11/1935, p. 13.

Anónimo (1935f): “Capítulo de fiestas”, La Vanguardia, Barcelona, 23/10/1935, p. 9.

Anónimo (1935g): “Casa Llibre”, La Vanguardia, Barcelona, 31/12/1935, p. 10.

Anónimo (1935h): "Fiestas, tes y «reveillons»”, La Vanguardia, Barcelona, 27/12/1935, p. 10.

Anónimo (1935i): "Las funciones del Liceo", La Vanguardia, Barcelona, 26/11/1935, p. 14.

Anónimo (1935j): "Noticias diversas", La Vanguardia, Barcelona, 26/12/1935, p. 8.

Anónimo (1935k): "Sesiones de cine”, La Vanguardia, Barcelona, 17/12/1935, p. 13.

Anónimo (19351): “Musica de «Jazz»”, La Vanguardia, Barcelona, 14/11/1935, p. 10.

Anónimo (1935m): “Oshima”, La Vanguardia, Barcelona, 08/11/1935, p. 22.

Anónimo (1935n): "Los actos de estos días”, La Vanguardia, Barcelona, 12/11/1935, p. 24.

Anónimo (1935ñ): “El gran festival de «La Viuda Alegre»”, L'Instant, Barcelona, 09/11/1935, p. 7.

Anónimo (1935o): “Qui ha guanyat?”, Mirador: setmanari de literatura, art i política, Barcelona, 06/06/1935, p. 1.

Anónimo (1935p): “En català!, En català!”, Mirador: setmanari de literatura, art i política, Barcelona, 12/12/1935, p. 1.

Anónimo (1936a): “Espectáculos”, La Vanguardia, Barcelona, 24/11/1936, p. 7.

Anónimo (1936b): “Un concierto de «Jazz»”, La Vanguardia, Barcelona, 21/01/1936, p. 10.

Anónimo (1936c): “La jornada”, La Vanguardia, Barcelona, 18/01/1936, p. 12.

Anónimo (1936d): “Oshima”, La Vanguardia, Barcelona, 05/01/1936, p. 20.

Anónimo (1937a): “Oshima”, La Vanguardia, Barcelona, 01/01/1937, p. 7.

Anónimo (1937b): “Oshima”, La Vanguardia, Barcelona, 31/12/1937, p. 7.

Anónimo (1939): "Esquela”, Hoja oficial de la provincia de Barcelona, Barcelona, 25/09/1939, p. 2.

Anónimo (1952): "Vieja raigambre de un edificio nuevo", La Vanguardia, Barcelona, 20/05/1952, p. 17.

Anónimo (1955a): “Abanicos en invierno, Carlos Ma Baró expone su colección”, Destino, Barcelona, 19/02/1955, p. 16. Anónimo (1955b): “Los siglos a través del abanico", Destino, Barcelona, 26/02/1955, p. 15.

Barlés Báguena, Elena (2003): “Luces y sombras en la historiografía del arte japonés en España”. En: Artigrama, 18, Zaragoza, pp. 23-82.

Barlés Báguena, Elena (2015): “El descubrimiento del arte japonés en Occidente durante la era Meiji”. En: Almazán Tomás, David / Barlés Báguena, Elena (eds.): La fascinación por el arte del País del Sol Naciente. El encuentro entre 
Japón y Occidente en la era Meiji (1868-1912) (cat. exp.). Zaragoza: Fundación Torralba Fortún y Fundación Japón, pp. 95-156. (Comisarios: David Almazán Tomás / Elena Barlés Báguena. Museo de Zaragoza, Zaragoza, 2015).

Baró Escalante, Carlos María (1955): El abanico a través de los siglos. Barcelona: Fomento de las Artes Decorativas.

Baró Escalante, Carlos María / Escoda, Juan (1957): Eventails anciens. Lausana: Payot.

Barreiro, Javier (2005): "La Fornarina y el origen de la Canción Española”. En: Asparkia. Investigación feminista, 16, Castellón de la Plana, pp. 27-40.

Blat Martínez, Antonio (2018): “Las relaciones Japón-España desde la negociación hasta la revisión del tratado de 1868”. En: Miñano Medrano, Santiago (ed.) (2018): Tratado de 1868: los cimientos de la amistad Japón-España. Madrid: Ministerio de Asuntos Exteriores, Unión Europea y Cooperación y Embajada del Japón en España, pp. 59-148.

Bru Turull, Ricard (2004): "Notes pel col·leccionisme d'art oriental a la Barcelona vuitcentista". En: Butlletí de la Reial Acadèmia Catalana de Belles Arts de Sant Jordi, Vol. XVIII, Barcelona, pp. 233-257.

Bru Turull, Ricard (2008): "Japanese influence on decorative arts in Barcelona". En: Design Discourse, Vol. IV, 1, Tokio, pp. 1-10.

Bru Turull, Ricard (2012): “Richard Lindau y el Museo de Arte Japonés de Barcelona”. En: Archivo Español de Arte, Vol. LXXXV, 337, Madrid, pp. 55-74.

Bru Turull, Ricard (2013): "Los amantes de la Luna. La fascinación por un nuevo Japón (1906-1936)”. En: Bru Turull, Ricard (dir.): Japonismo. La fascinación por el arte japones (cat. exp.). Barcelona: Obra Social La Caixa, pp. 186221. (Comisario: Ricard Bru Turull. CaixaForum, Barcelona, 14/06/2013-15/09/2013).

Bru Turull, Ricard (2016): “Japón en la Exposición Universal de 1888”. En: スペイン・ラテンアメリカ美術史研究, 17, Tokio, pp. 41-51.

Bru Turull, Ricard (2018): "El japonismo en Lluís Domènech i Montaner y su colección de libros ilustrados japoneses". En: Archivo Español de Arte, Vol. XCI, Vol. 363, Madrid, pp. 285-300.

Cavía Naya, Victoria (2013): "Mujeres, teatro, música y variedades: de las boleras y flamencas a las bailarinas de danza española (1885-1927)”. En: Cuadernos de música iberoamericana, XXV-XXVI, Madrid, pp. 51-73.

Cerón Gómez, Juan Francisco / Martínez González, Juan (1999): Cien años de cine en Lorca. Murcia: Universidad de Murcia.

Donovan, Mary Kate (2016): "Mapping Chinatown in 1920s and 1930s Barcelona: How el Raval Became el Barrio Chino". En: Arizona Journal of Hispanic Cultural Studies, 20, Tucson, pp. 9-27.

Ealham, Chris (2007): "Una «geografía imaginada»: ideología, espacio urbano y protesta en la creación del 'Barrio Chino’ de Barcelona, c. 1835-1936”. En: Historia Social, 59, Valencia, pp. 55-76.

F (1888): "La instalación japonesa", La Vanguardia, Barcelona, 31/05/1888, p. 4.

Fernández González, Miquel (2012): Matar al “Chino”. Entre la revolución urbanística y el asedio urbano en el barrio del Raval de Barcelona. Tesis Doctoral dirigida por Manuel Delgado Ruiz / Roger Martínez Sanmartí, Departament d'Antropologia cultural i Història d'Amèrica i Africa, Universitat de Barcelona.

Fontbona de Vallescar, Francesc (dir.) (1999): Repertori d'exposicions individuals d'art a Catalunya (fins a l'any 1938). Barcelona: Institut d'Estudis Catalans.

García Llansó, Antonio (1888): “La Exposición Universal de Barcelona XV. La sección china”, La Ilustración, Barcelona, 08/07/1888, pp. 438-439.

García, Jorge (2012): “El trazo del jazz en España”. En: García, Jorge (dir.): El ruido alegre, jazz en la BNE (cat. exp.). Madrid: Biblioteca Nacional de España, pp. 17-71. (Comisario: Jorge García. Biblioteca Nacional de España, Madrid, 28/11/2012-24/02/2013).

Gasch, Sebastià (1932): "Reformes il-lògiques", Mirador: setmanari de literatura, art i política, Barcelona, 26/05/1932, p. 9.

Ginés Blasi, Mònica (2013): El col-leccionisme entre Catalunya i la Xina (1876-1895). Tesis Doctoral dirigida por Mireia Freixa Serra / Josep María Fradera, Departamento de Historia del Arte, Universidad de Barcelona.

Ginés Blasi, Mònica (2015): “Art i cultura material de la Xina en les col·leccions privades de la Barcelona vuitcentista”. En: Locus Amoenus, 13, Barcelona, pp. 139-155.

Ginés Blasi, Mònica (s/f): El coleccionismo de arte chino. Archivo China España 1800-1950. Universitat Oberta de Catalunya, http://ace.uoc.edu/exhibits/show/china-en-espana/coleccionismo-de-arte-chino [Consulta: 01/01/2020].

Gómez Pradas, Muriel (2017): "El crucero universitario a "Extremo Oriente” de 1935. Un viaje a Japón y dos destinos". En: Mirai. Estudios Japoneses, 1, Madrid, pp. 225-235.

Hernández-Cros, Josep Emili (dir.) (1987): Catàleg del Patrimoni Arquitectònic Històrico-Artístic de la Ciutat de Barcelona. Barcelona: Ajuntament de Barcelona.

Lara, Do de (1900): “En el Teatro Japonés”, La Correspondencia Militar, Madrid, 01/10/1900, p. 2.

Mendoza, Carlos (1888): "Impresiones de la Exposición Universal de Barcelona”, La Ilustración Ibérica, Barcelona, 18/08/1888, pp. 515-517.

Oliveres, Camil (1935): “Sala Oshima de la Casa Llibre: Presentació de l'Orquestra de «Jazz» «Els 16 artistes reunits»”, La Humanitat, Barcelona, 17/11/1935, p. 5.

Passarell, Jaume (1936): "Dibuxos de Ricard Opisso", Mirador: setmanari de literatura, art i política, Barcelona, 13/02/1936, p. 7.

Planes, Josep Maria (1929): “La Criolla”, Mirador: setmanari de literatura, art i política, Barcelona, 30/05/1929, p. 2. 
Soiza Reilly, Juan José (1908): “La vida íntima de Mariano de Cavia”, Caras y caretas, Buenos Aires, 25/05/1908, pp. 6566.

Tomás, Joan (1934): “Amb Douglas Fairbanks, pare i fill, a l'Apolo i la Criolla”, Mirador: setmanari de literatura, art $i$ política, Barcelona, 29/03/1934, p. 4.

Trillas Blázquez, Gabriel (1935): "Noches de Barcelona. Seis horas continuas de "cabaret” con espectáculo, por una peseta", Crónica, Madrid, 25/08/1935, s.n.

Villar, Paco (2013): Barcelona, ciudad de cafés. Barcelona: Ediciones Invisibles y Ajuntament de Barcelona.

www.britishpathe.com (2019): The Girls from Oshima - Japan. British Pathé. https://www.britishpathe.com/video/thegirls-from-oshima-japan/ [Consulta: 28/12/2019].

www.pop.culture.gouv.fr (2019a): Ancien café-concert Le Bataclan. Ministère de la Culture. https://www.pop.culture. gouv.fr/notice/merimee/PA00086554 [Consulta: 29/03/2020].

www.pop.culture.gouv.fr (2019b): Restaurant Pavillon chinois, puis Grand Café. Ministère de la Culture. https://www. pop.culture.gouv.fr/notice/merimee/IA95000388 [Consulta: 29/03/2020]. 